\title{
Morfologia craniana dos remanescentes ósseos humanos da Lapa do Santo, Lagoa Santa, Minas Gerais, Brasil: implicações para o povoamento das Américas \\ Cranial morphology of the human skeletal remains from Lapa do Santo, Lagoa Santa, Minas Gerais, Brazil: implications for the settlement of the Americas
}

\author{
Walter Alves Neves', Mark Hubbe", André Menezes Strauss"II, Danilo Vicensotto BernardoIV \\ Universidade de São Paulo. São Paulo, São Paulo, Brasil \\ "The Ohio State University. Columbus, USA \\ IIIMax Planck Institute for Evolutionary Anthropology. Leipzig, Alemanha \\ IV Universidade Federal do Rio Grande. Rio Grande, Rio Grande do Sul, Brasil
}

\begin{abstract}
Resumo: A região cárstica de Lagoa Santa tem sido de suma importância para as discussões sobre o tempo e o modo da dispersão dos primeiros americanos. A Lapa do Santo, escavada na última década, originou uma das maiores coleções de esqueletos humanos desta região. Neste trabalho, investigamos as afinidades morfológicas dos esqueletos da Lapa do Santo com outras amostras esqueletais de Lagoa Santa e da Colômbia, contextualizando-as dentro da variação morfocraniana existente hoje no planeta. Nossas análises, realizadas sobre um total de 2.059 crânios (1.071 masculinos e 988 femininos), estão baseadas em duas abordagens multivariadas, com o objetivo de caracterizar a variabilidade intra e intergrupos das 24 séries incluídas no trabalho. Nossos resultados mostram que os crânios da Lapa do Santo, bem como de outras séries de Lagoa Santa, não mostram níveis mais elevados de variabilidade intragrupal do que as séries modernas usadas como comparação, sugerindo que elas representam uma mesma população biológica. Concluímos também que os esqueletos mais antigos da América do Sul, incluindo os da Lapa do Santo, mostram fortes afinidades morfológicas com as populações australo-melanésias e da ilha de Páscoa. Tais resultados sugerem que houve um aumento na diversidade biológica no continente americano durante o Holoceno Médio, possivelmente devido ao influxo de diversidade extracontinental após a colonização inicial das Américas.
\end{abstract}

Palavras-chave: Primeiros americanos. Afinidades morfológicas. Análise multivariada. Paleoamericanos.

\begin{abstract}
The karstic region of Lagoa Santa has been highly important for the discussion about the tempo and mode of the initial human dispersal into the Americas. Lapa do Santo rockshelter, excavated during the past decade, represents to date one of the largest collections of early Holocene human remains recovered from the region. Here we analyze the morphological affinities of Lapa do Santo individuals with other early series from Lagoa Santa and Colombia, contextualizing them within the modern human cranial variation across the planet. Our analyses, performed on a total of 2,059 skulls (1,071 males and 988 females), are based on complementary multivariate approaches, aiming to characterize the within-group variance and the between-group morphological affinities of the 24 series included in the analyses. Our results indicate that Lapa do Santo, and other Lagoa Santa, individuals do not present higher levels of within-group variation than modern human groups, supporting the idea that they represent a single biological population. When compared to worldwide series, the early South American groups, Lapa do Santo included, share high morphological affinities among themselves and with Australo-Melanesian and Easter Island groups. Taken together, these results suggest an increase of biological diversity in the continent during the Holocene, possibly a result of the influx of new extra-continental diversity after its initial settlement.
\end{abstract}

Keywords: First americans. Morphological affinities. Multivariate analysis. Paleoamericans.

NEVES, Walter Alves; HUBBE, Mark; STRAUSS, André Menezes; BERNARDO, Danilo Vicensotto. Morfologia craniana dos remanescentes ósseos humanos da Lapa do Santo, Lagoa Santa, Minas Gerais, Brasil: implicações para o povoamento das Américas. Boletim do Museu Paraense Emílio Goeldi. Ciências Humanas, v. 9, n. 3, p. 715-740, set.-dez. 2014. DOI: http://dx.doi.org/10.1590/1981-81222014000300012. Autor para correspondência: Danilo Vicensotto Bernardo. Universidade Federal do Rio Grande. Instituto de Ciências Humanas e da Informação. Avenida Itália, km 8 - Carreiros. Rio Grande, RS, Brasil. CEP 96203-000 (danilobernardo@furg.br).

Recebido em 20/11/2013

Aprovado em 13/10/2014

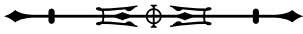




\section{INTRODUÇÃO}

Nas últimas quatro décadas, o debate sobre o povoamento das Américas ocorre em torno de quatro áreas do conhecimento: genética, linguística, arqueologia e morfologia craniana e dentária. Sem exceção, cada uma destas áreas demonstrou que os processos associados com a chegada do ser humano ao Novo Mundo foram complexos e difíceis de ser descritos por modelos simples ou lineares. É notória, por exemplo, a falta de consenso que existe na interpretação de dados, tanto dentro de cada área de conhecimento como entre elas'. A morfologia craniana, apesar de sua importância no estudo das origens humanas em outras partes do planeta (por exemplo, os de Howells, 1973, 1989; Hanihara, 1996), permaneceu, nesse período, no entanto, quase silenciosa no que se refere ao povoamento inicial do continente americano. Essa situação mudou apenas no final do século $X X$, com a publicação dos trabalhos pioneiros de Neves e Pucciarelli (1989, 1990, 1991), na América do Sul, e de Steele e Powell $(1992,1993)$ e Powell e Steele (1992), na América do Norte.

Um dos problemas frequentemente citados para explicar essa ausência de trabalhos sobre morfologia craniana comparada é que remanescentes ósseos humanos de grande antiguidade são incomuns no Novo Mundo. Apenas para exemplificar, espécimes mais antigos do que sete mil anos em toda a América do Norte são raríssimos e encontrados de forma dispersa e isolada (Jantz e Owsley, 2001; Waguespack, 2007).

Nesse contexto, a região arqueológica de Lagoa Santa é uma feliz exceção (Bernardo e Neves, 2009). A região, localizada no centro-leste brasileiro, é reconhecida como rica fonte de fósseis da transição Pleistoceno/ Holoceno, incluindo remanescentes ósseos humanos datados de até 11000 anos AP (Neves e Hubbe, 2005). Tais remanescentes são conhecidos desde os anos 1840, com o trabalho pioneiro de Peter Lund, naturalista dinamarquês que pesquisou intensivamente as cavernas e os abrigos da região, entre 1835 e 1844 (Neves e Piló, 2008). Lund exumou aproximadamente 30 esqueletos humanos da Gruta do Sumidouro, nos anos de 1842 e 1843 (Lund, 1844, 1846). Para ele, os esqueletos humanos eram de grande antiguidade, tendo em vista que foram encontrados em associação com uma rica coleção de fósseis de megafauna extinta (Lund, 1844, 1846). A descrição feita por Lund sobre a grande antiguidade e a natureza dos esqueletos do Sumidouro chamou grande atenção, transformando a região em um dos pilares centrais na discussão sobre a antiguidade, origem e características dos primeiros grupos sul-americanos (Lacerda e Peixoto, 1876; Kollmann, 1884; Ten Kate, 1885; Quatrefages, 1887; Hansen, 1888; Virchow, 1892; Hrdlicka, 1912).

Muitos especialistas escavaram na região de Lagoa Santa desde então. Entretanto, a grande maioria dos esqueletos humanos exumados foi coletada por amadores ou durante a fase pré-científica da arqueologia brasileira (Prous, 1992, 1997). Portanto, muito desse material advém de escavações sem rígido controle estratigráfico.

Duas exceções destacam-se nesse contexto: o material esqueletal humano obtido por Wesley Hurt e Oldemar Blasi, em 1956 (Hurt e Blasi, 1969), e o esqueleto humano, posteriormente apelidado de Luzia por um dos autores (WAN), que foi recuperado na Lapa Vermelha IV, em 1975, pela missão franco-brasileira liderada por Annette Laming-Emperaire (Laming-Emperaire, 1979).

De 2000 a 2009, os autores desenvolveram um projeto de longo prazo na área de Lagoa Santa, com três objetivos principais: 1) datar, por AMS, os remanescentes ósseos humanos já institucionalizados no Brasil e no exterior, incluindo a coleção Lund na Dinamarca; 2) visitar os sítios clássicos de Lagoa Santa, com vistas a observar e, se possível, compreender sua estratigrafia; e 3) escavar novos sítios usando métodos precisos de escavação. Em conjunto, estes três eixos de ação tiveram como objetivos resolver os principais problemas contextuais das coleções

\footnotetext{
1 Ver Neves et al. (2013) para uma discussão mais aprofundada sobre o tema.
}

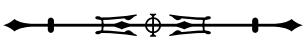


escavadas anteriormente na região e gerar novas coleções bem contextualizadas que permitissem testes de hipóteses mais específicos sobre o estilo de vida e as características biológicas e culturais dos grupos que inicialmente ocuparam Lagoa Santa (Neves et al., 2007a; Araujo et al., 2012).

O novo contexto cronológico gerado pelo projeto mostrou que restos humanos pleistocênicos são raros na região e apenas Luzia (Lapa Vermelha IV) apresenta datas do final do Pleistoceno (Feathers et al., 2010). Apesar da presença de datas pleistocênicas nos níveis mais baixos do pacote arqueológico dos abrigos escavados (Araujo et al., 2008), o uso sistemático desses espaços como cemitérios não começou antes de aproximadamente 9 mil anos atrás, sugerindo uma possível mudança cultural na região durante esse período.

Fora dos abrigos, prospecções em margens de lagos encontraram artefatos líticos datados em 8300 anos AP (Araujo \& Feathers, 2008; Araujo et al., 2013), o que sugere um possível incremento no uso logístico dos recursos locais por populações que se estabeleceram permanentemente em Lagoa Santa durante o início do Holoceno. Dentro dos abrigos rochosos, o padrão de enterramentos da Lapa do Santo (ver detalhes a seguir) apoia esta ideia e sugere um crescimento de complexidade associado com práticas sociais, em particular no que se refere ao tratamento dos mortos (Strauss, 2010, 2011, 2012; Strauss et al., 2011).

Aparentemente, a incorporação de recursos locais não incluiu a exploração sistemática de mamíferos de grande porte, que ainda rondavam a região nos primeiros milênios do Holoceno (Hubbe et al., 2009, 2012, 2013), sugerindo que os grupos caçadores-coletores de Lagoa Santa não se especializaram na caça de megafauna. Este quadro é favorecido pela presença exclusiva de animais de pequeno e médio porte (especialmente veado, Mazama sp.) no registro arqueológico local, e pela presença de uma indústria lítica composta de lascas pequenas e microlascas de quartzo, com pouquíssimas mudanças durante os três mil anos de presença humana na região (Araujo et al., 2008). Complementando esse quadro, os grupos locais parecem ter ingerido quantidades maiores de alimentos cariogênicos, elementos vegetais ricos em carboidratos (Edmondson, 1990), em relação aos grupos de caçadores-coletores típicos, resultando em prevalência de cáries, superior à esperada entre os grupos de Lagoa Santa (Neves e Cornero, 1997; Neves e Kipnis, 2004; Da-Gloria, 2012).

É provável que a região tenha sido abandonada parcialmente durante o Holoceno Médio (entre 6000 e 3000 anos AP), devido a uma grande instabilidade climática que teria obrigado grupos humanos a se moverem para regiões com fontes de água mais estáveis (Araujo et al., 2005). Após 3000 anos AP, a região voltou a ser ocupada por grupos que não apresentavam nenhuma relação cultural com os grupos antigos de Lagoa Santa. Este quadro, entretanto, pode ter sido mais complexo, dado que as escavações na Lapa do Santo demonstram presença humana durante o Holoceno Médio, sugerindo uma dinâmica de ocupação mais complexa do que se esperaria no caso de a região ter sido abandonada durante este período (Araujo et al., 2013).

Em resumo, Lagoa Santa representa um rico registro histórico dos primeiros milênios do Holoceno, momento durante o qual os grupos caçadores-coletores locais ocuparam de maneira sistemática a região, especializandose nos recursos e nas características da paisagem local e desenvolvendo traços culturais específicos, que os discerniram de grupos humanos em outros contextos da América do Sul (Araujo et al., 2012).

Dentro deste novo marco interpretativo, o projeto escavou dois abrigos com pacotes arqueológicos densos (Neves et al., 2007a) e presença de remanescentes ósseos humanos: Lapa das Boleiras (Araujo, 2010) e Lapa do Santo (Neves et al., 2012a; Bernardo et al., 2012). Na Lapa do Santo, foco do presente artigo, foram exumados 26 indivíduos, datados entre aproximadamente 9000 e 6000 anos $\mathrm{AP}$, que representam uma das maiores coleções de restos humanos antigos com contextos arqueológicos detalhados do continente (Strauss, 2011; Strauss et al., 2011; Neves et al., 2012b; Bernardo et al., 2012). O presente trabalho tem

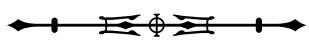


por objetivo apresentar as características morfológicas desta coleção, por meio de uma análise comparativa de afinidades biológicas com outros grupos que habitaram as Américas e outras regiões do planeta. Com a análise comparativa dos indivíduos da Lapa do Santo, deseja-se contribuir para a discussão das características biológicas da população que habitou Lagoa Santa sistematicamente por quase três mil anos e apontar possíveis implicações dessas características para a questão da origem do ser humano na América.

\section{CONTEXTO ARQUEOLÓGICO E FUNERÁRIO DA LAPA DO SANTO}

A Lapa do Santo encontra-se dentro da Área de Proteção Ambiental (APA) Carste de Lagoa Santa, no município de Matozinhos, em Minas Gerais (Figura 1). A coordenada UTM do sítio é 7845985 e 600870E (Referencial Geodésico WGS - 84, Fuso 23K Sul). Trata-se de uma caverna que se projeta para dentro de um enorme paredão calcário, com cerca de 30 metros de altura, cuja entrada apresenta ampla

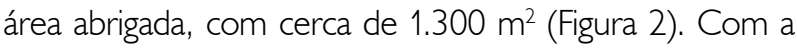
exceção de uma única sondagem, que foi realizada dentro da caverna, todas as demais intervenções arqueológicas no sítio foram feitas em uma área abrigada, a qual é delimitada, de um lado, pela presença da caverna e, do outro, pela presença da mata de capoeira. Essa área apresenta cerca de 60 metros de extensão, no sentido Norte-Sul, e 30 metros, no sentido Leste-Oeste (Figura 3). O terreno do abrigo é caracterizado por uma forte inclinação descendente na direção norte, gerando um desnível de cerca de 10 metros. No extremo mais rebaixado, ao norte, encontrase o sumidouro de uma possível lagoa temporária que se forma em épocas de chuva intensa.

Nas etapas iniciais de escavação, foram feitas sondagens ao longo de praticamente toda a extensão da área abrigada, com o intuito de avaliar o potencial do sítio. Durante esse processo, ficou bem caracterizado que a região sul do abrigo apresentava um pacote potencialmente intacto, com idades que remetiam ao Holoceno Inicial. A partir de então, essa parte do sítio tornou-se a área principal de escavação, e uma superfície ampla passou a ser escavada por meio da decapagem por níveis naturais (Figura 3). Essa superfície foi escavada entre os anos de 2001 e 2009, quando o sítio foi fechado. Durante esse período, foram exumados 26 sepultamentos humanos, com idades de até 8800 anos AP. Esse material trouxe grande contribuição para o entendimento das práticas mortuárias da região de Lagoa Santa, em particular, e da América do Sul, em geral. A Figura 4 apresenta imagens do sítio arqueológico durante as atividades de escavação, em diferentes etapas.

A diversidade de práticas funerárias na Lapa do Santo (Strauss, 2010, 2011) contradiz a visão da academia sobre as práticas mortuárias de Lagoa Santa, segundo a qual os enterros eram simples, expeditos e homogêneos (Walter, 1958; Prous, 1992; Neves et al., 2004; Neves e Hubbe, 2005). Na ausência de uma arquitetura sofisticada ou de ricos acompanhamentos funerários, a elaboração dos rituais mortuários passava pelo uso do próprio corpo do falecido como símbolo. Ainda que existam outros casos na região (Neves et al., 2002), é no 'Padrão Funerário 1', da Lapa do Santo, datado entre 8800 e 8200 anos AP, que essa lógica se manifesta de forma mais intensa e cristalina, expressa na forma de sepultamentos desarticulados, compostos por crânios individualizados, fardos de ossos (compostos por até três indivíduos), marcas de corte, chanfros, extração de dentes, seleção de partes anatômicas, exposição ao fogo e aplicação de ocre. Ao mesmo tempo, a presença de esqueletos articulados e semiarticulados, entre os quais o caso mais antigo de decapitação em todo o continente americano (Neves et al., 2012b), atesta que a seleção de partes anatômicas e sua consequente remoção eram praticadas logo após a morte, enquanto os tecidos moles ainda estavam presentes. Posteriormente, os ossos eram realocados e dispostos de acordo com uma série de princípios muito bem definidos. Notadamente, por meio desses ossos, procedia-se à retificação de diretrizes lógicas que, possivelmente, refletiam aspectos da própria cosmovisão daqueles grupos. A clareza com que era expressa a dupla dicotomia entre 'adulto' e 'subadulto' e 


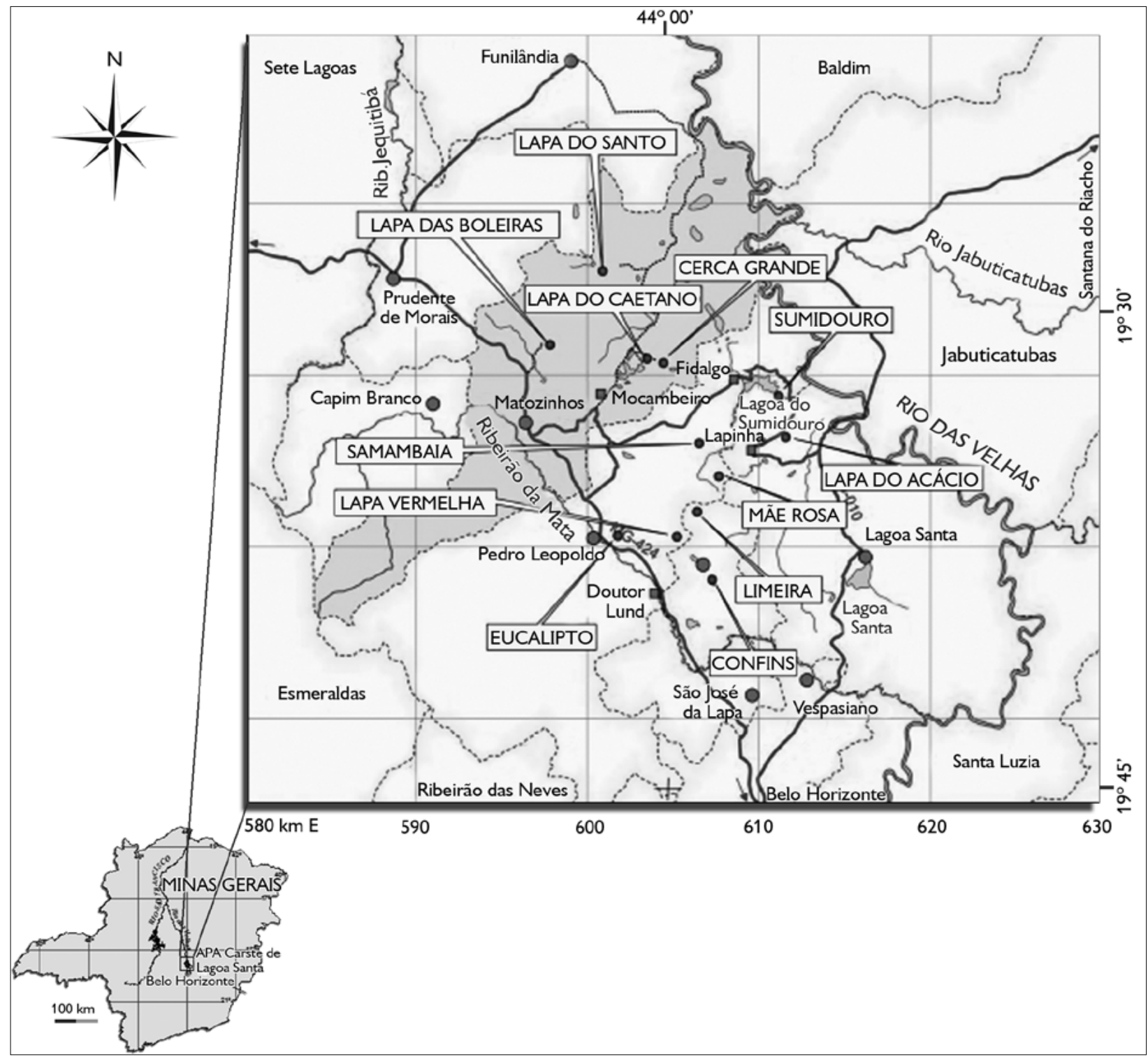

Figura 1. Mapa do estado de Minas Gerais com a localização geográfica da Área de Proteção Ambiental Carste de Lagoa Santa (em destaque), mostrando sítios arqueológicos da área, incluindo a Lapa do Santo (adaptado de Piló, 2002).

entre 'crânio' e 'pós-crânio', a dicotomia entre 'diáfise' e 'epífise', e a dicotomia entre 'dente' e 'alvéolo vazio' atribui, inevitavelmente, um tom levi-straussiano à lógica adotada. A consistência com que esses princípios se manifestam, e a semelhança técnica através da qual se realizam, poderia indicar a existência de indivíduos especializados nesse processo (Strauss, 2010).
A partir de 8000 anos AP, entretanto, observase uma drástica mudança nas práticas mortuárias do sítio. A ênfase na manipulação perimortem do corpo é abandonada e, em seu lugar, aparecem sepultamentos francamente secundários, que são caracterizados por covas de contorno circular muito bem delimitado, com cerca de 40 centímetros de diâmetro e 30

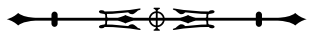



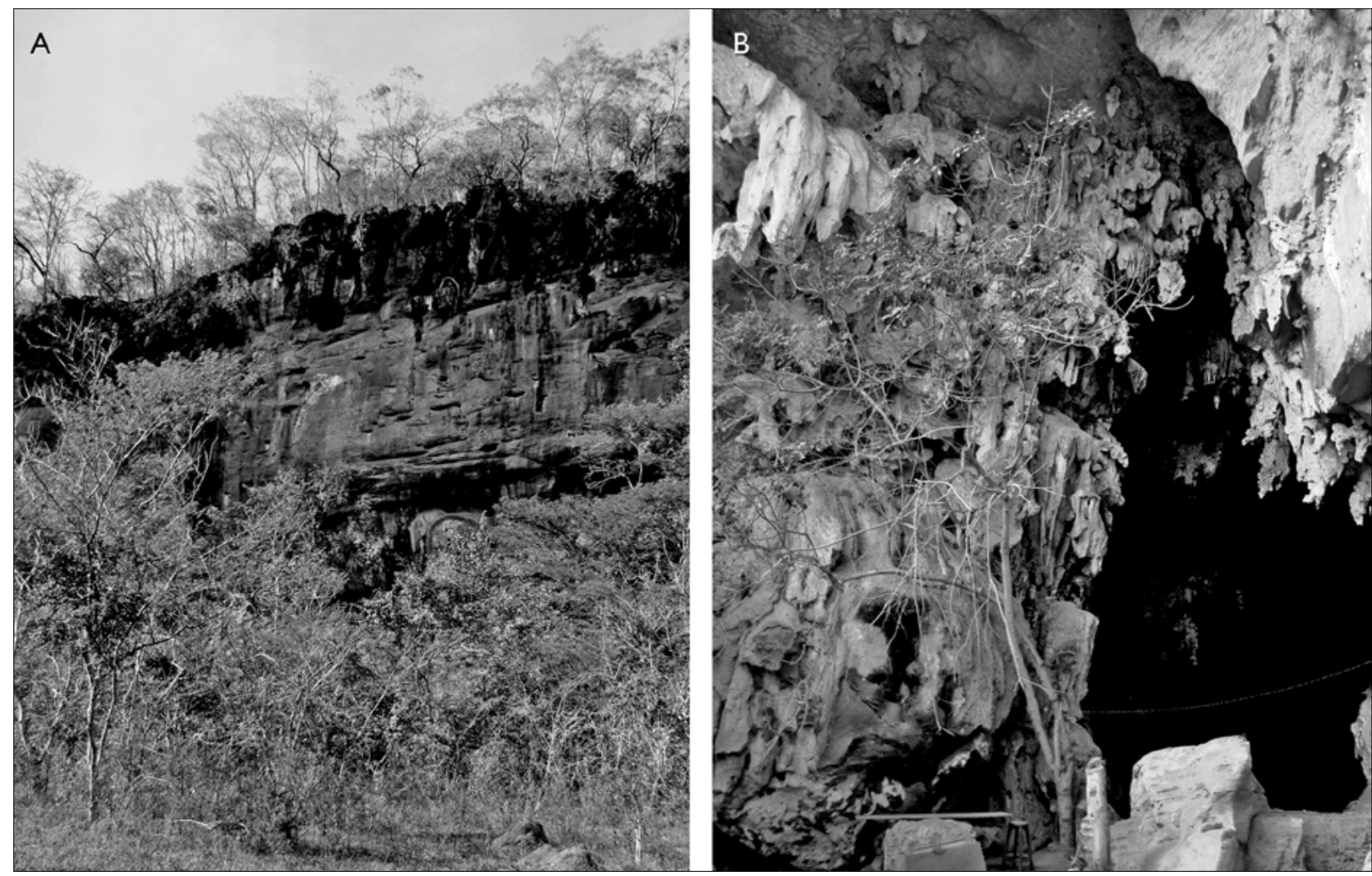

Figura 2. Área de Proteção Ambiental Carste de Lagoa Santa, MG, Brasil: A) maciço calcário sob o qual se implanta o sítio Lapa do Santo (abrigo sob rocha); B) detalhe da entrada da área abrigada. Fotos: acervo do Laboratório de Estudos Evolutivos Humanos (LEEH), do Instituto de Biociências da Universidade de São Paulo (IB/USP).

centímetros de profundidade, às vezes menos. Cada cova era totalmente preenchida pelos ossos de um único esqueleto, cuja disposição apresentava pouca ou nenhuma lógica anatômica. No caso de indivíduos adultos, muitas vezes os ossos longos eram quebrados ao meio antes ou durante o processo de enterramento. Em alguns casos, as covas eram recobertas por estruturas muito características, formadas pelo empilhamento de diversos blocos de pedra, com o tamanho médio de um punho (Neves et al., 2008; Strauss, 2010). As Figuras 5 e 6 apresentam, respectivamente, exemplos desses extremos de enterramentos primários e secundários observados na Lapa do Santo.

Uma mudança tão radical nas práticas funerárias deve refletir algum tipo de alteração na própria organização social daqueles grupos. Até o presente momento, os sepultamentos são a única fonte que aponta para essa mudança no registro arqueológico da região de Lagoa Santa, por volta de 8000 anos AP. Conforme outros estudos venham a ser realizados, será possível avaliar se tal mudança foi fruto de uma reorganização interna dos grupos que já habitavam a região ou se implica a chegada de uma nova população e/ou de uma nova tradição cultural em Lagoa Santa no período em questão.

\section{MATERIAL E MÉTODOS}

As análises de afinidades morfológicas dos indivíduos da Lapa do Santo consideraram os sete crânios mais íntegros e livres de deformações tafonômicas após o processo de cura e restauro (Neves, 1988; Lessa, 2011).

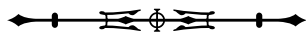




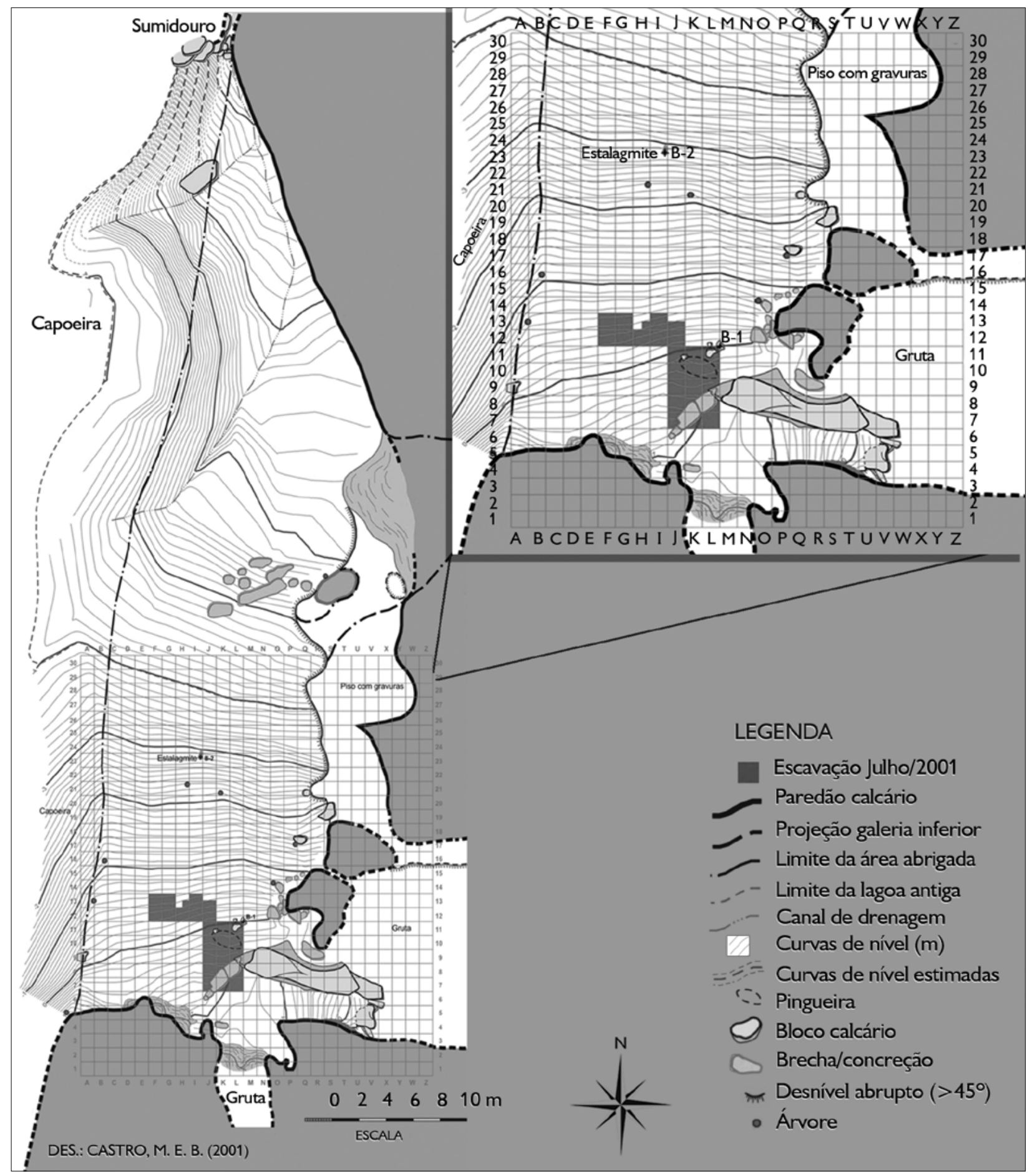

Figura 3. Planta baixa da área abrigada do sítio Lapa do Santo, com o gradeamento espacial para a localização das unidades de escavação. Quadrículas preenchidas (pintadas) correspondem às unidades escavadas. Fonte: Laboratório de Estudos Evolutivos Humanos (USP), Projeto "Origens e Microevolução do Homem na América”, Sítio Arqueológico "Lapa do Santo", Município de Matozinhos (Minas Gerais), Julho de 2001. Notas: coordenadas e altitudes arbitradas; Norte magnético em Julho/2001; equidistância das curvas de nível de 10 cm.

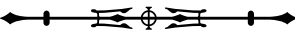



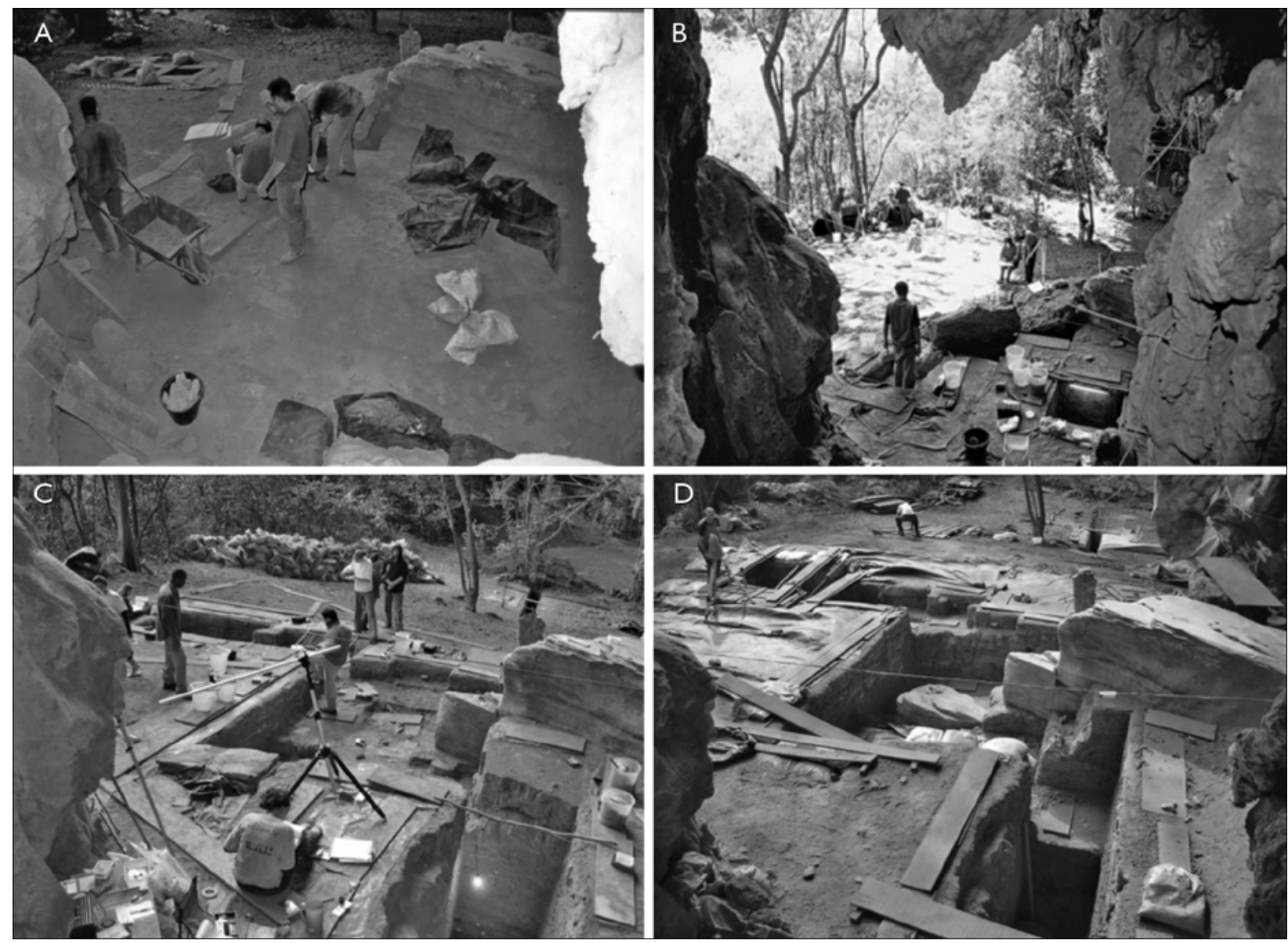

Figura 4. Fotos da área central da Lapa do Santo, em diferentes etapas (anos) de trabalho: A) superfície ainda não escavada, etapa de 2001; B) unidades isoladas, início dos trabalhos na etapa de 2003; C) etapa de 2005, superfície ampliada já em escavação; D) evidenciação do embasamento rochoso do sítio em vários pontos da superfície ampliada, etapa de 2008 (adaptado de Strauss, 2010). Fotos: acervo do Laboratório de Estudos Evolutivos Humanos (LEEH), do Instituto de Biociências da Universidade de São Paulo (IB/USP).

Tais indivíduos, todos adultos, foram exumados em intervenções de campo desenvolvidas pela equipe do Laboratório de Estudos Evolutivos Humanos, entre 2001 e 2009 (Neves et al., 2008; Strauss, 2011). Detalhes sobre o contexto de cada um destes indivíduos podem ser encontrados na Tabela 1. Os crânios da Lapa do Santo foram comparados com amostras de referência de outros sítios de Lagoa Santa, grupos do início e do meio do Holoceno da Colômbia e grupos recentes representativos da diversidade morfológica mundial do banco de dados de Howells (1973, 1989, 1999).
A série de Lagoa Santa é composta por indivíduos de dois outros sítios da região com amostras razoáveis de crânios humanos: o Sumidouro e o Complexo de Cerca Grande. Os crânios do Sumidouro provêm das escavações de Lund na gruta de mesmo nome, e representam, até o momento, uma das maiores coleções osteológicas da região. Entretanto, os esqueletos do Sumidouro foram recuperados de um contexto paleontológico (ou seja, os esqueletos não se encontravam em enterramentos formais), perturbados pela ação constante da variação do nível freático da Lagoa do Sumidouro, que manteve a

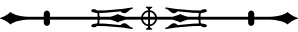




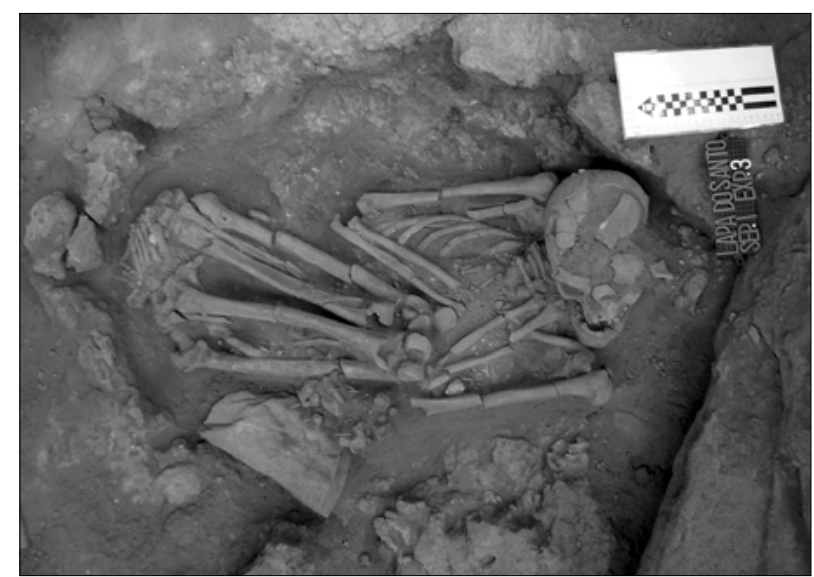

Figura 5. Sepultamento 1 da Lapa do Santo, encontrado em 2001 e completamente exumado na campanha de 2009. Exemplo de enterramento primário observado no sítio. Fotos: acervo do Laboratório de Estudos Evolutivos Humanos (LEEH), do Instituto de Biociências da Universidade de São Paulo (IB/USP).

caverna inundada por longos períodos de tempo. Ainda assim, o material do Sumidouro possui uma data mínima de 8500 anos AP (Piló et al., 2004, 2005)².

O complexo de Cerca Grande reúne vários abrigos, dos quais foram exumados esqueletos humanos escavados por Wesley Hurt e Oldemar Blasi durante a década de 1950. A maioria dos sepultamentos de Cerca Grande foi encontrada em sepulturas rasas, algumas vezes demarcadas por blocos calcários e sem a presença de cultura material associada (Hurt e Blasi, 1969). Os esqueletos de Cerca Grande estão datados ao redor de 8200 anos AP (Hurt e Blasi, 1969; Neves et al., 2004), e detalhes sobre seu contexto arqueológico e afinidades morfológicas podem ser encontrados em Neves et al. (2004).

Os 18 crânios melhor preservados - isto é, mais íntegros do ponto de vista morfológico - de Sumidouro e de Cerca Grande formam a série comparativa de Lagoa Santa neste estudo. O material dos dois sítios foi unido em uma única série para aumentar seu tamanho amostral (série Lagoa Santa), dada a alta afinidade

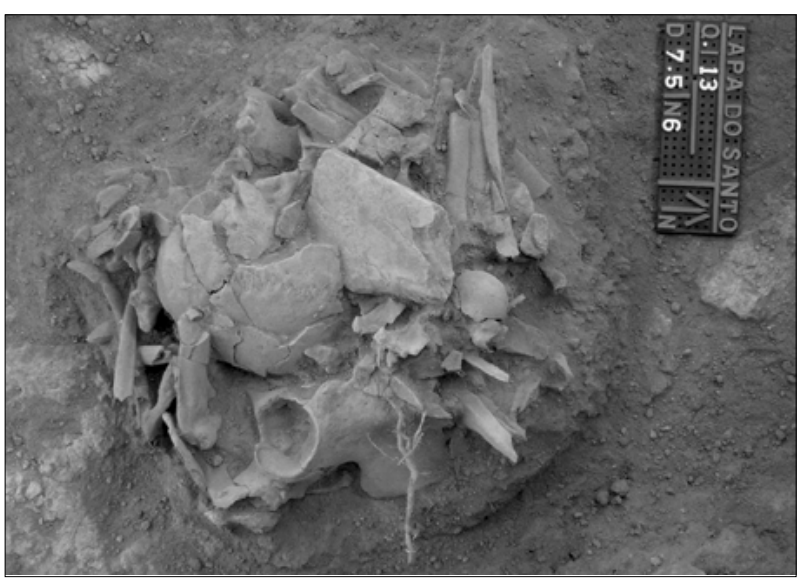

Figura 6. Sepultamento 15 da Lapa do Santo, exumado em 2005. Exemplo de enterramento secundário observado no sítio. Fotos: acervo do Laboratório de Estudos Evolutivos Humanos (LEEH), do Instituto de Biociências da Universidade de São Paulo (IB/USP).

biológica entre os indivíduos, estabilizando, desta forma, a variância intrassérie.

A série Colômbia inclui esqueletos do início e do meio do Holoceno da Savana de Bogotá, datados entre 10000 e 3000 mil anos AP (Neves et al., 2007c). Apesar da amplitude temporal do material da Savana de Bogotá, estudos anteriores demonstraram que todos os grupos da região apresentam altos níveis de afinidade morfológica, justificando sua inclusão em uma única série comparativa ${ }^{3}$.

As séries recentes de Howells (1973, 1989, 1999) representam a morfologia de grupos humanos modernos autóctones no planeta. Cada uma das séries Howells contém pelo menos 50 indivíduos de ambos os sexos, e o banco possui pelo menos três séries de cada continente, permitindo, assim, inferir a diversidade interna de cada macrorregião geográfica do planeta na atualidade. Aqui foram incluídas 20 das séries Howells, cujos detalhes podem ser encontrados em Howells (1973, 1989). A Tabela 2 lista as séries de referência adotadas, incluindo as de Lagoa Santa e Colômbia, bem

2 Detalhes sobre o material do Sumidouro podem ser encontrados em Neves et al. (2007b).

Detalhes sobre o material colombiano podem ser encontrados em Neves et al. (2007c).

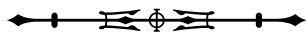


como detalhes sobre seu tamanho amostral e afiliação cronológica e geográfica.

As análises de afinidades morfológicas deste artigo basearam-se em 22 medidas craniométricas tomadas de cada indivíduo (Tabela 3), seguindo o protocolo de Howells (1973)4 . Com a exceção das séries do banco de dados de Howells (1973, 1989, 1999), os indivíduos incluídos nesta análise foram medidos pelo autor principal (WAN), para minimizar erros interobservadores. A seleção das variáveis incluídas nas análises foi realizada para minimizar o número de valores ausentes no banco de dados final. A Tabela 3 apresenta os valores médios e desvios-padrões de cada medida em cada população, e o Apêndice apresenta as medidas originais dos indivíduos da Lapa do Santo, inéditos até o momento. Mesmo com a seleção de variáveis, valores ausentes não foram completamente eliminados das séries arqueológicas, que apresentaram entre 1,0 e $12,2 \%$ de medidas faltantes. Os valores ausentes foram estimados antes das análises estatísticas multivariadas, por meio de regressões múltiplas sobre a média global de todas as séries incluídas nas análises ${ }^{5}$.

As afinidades morfológicas entre os crânios da Lapa do Santo e as séries de referência foram analisadas por meio de uma combinação de métodos. Inicialmente, foi calculado o coeficiente de variância médio (CV) para cada uma das séries analisadas. Coeficientes de variância foram utilizados aqui para estimar a variância interna de cada grupo e para analisar se as séries Lagoa Santa e Lapa do Santo, em particular, apresentam níveis de variância superiores ao observado em populações atuais (séries Howells), o que poderia ser indicativo de que as séries antigas representam mais de uma população biológica. Os CV foram obtidos pela razão entre o desvio padrão de cada variável e a sua média. Já os $C V$ médios para cada população foram obtidos por meio da média dos CV para cada variável (Bernardo, 2012).
As afinidades morfológicas entre séries foram acessadas por meio de duas análises multivariadas complementares: Análise de Componentes Principais (ACP) e dendrograma baseado nas distâncias de Mahalanobis entre grupos. A ACP resume a variância expressa por múltiplas variáveis em novas variáveis ortogonais (componentes principais), que evidenciam os eixos de maior variância entre as séries quando todas as variáveis são consideradas em conjunto (Hair Jr. et al., 2005). Portanto, a ACP nos permite inferir informações quanto às relações de afinidades morfológicas entre as séries quando apenas os eixos de maior variância entre elas são considerados. Os componentes principais foram extraídos da matriz de covariância entre as séries, uma vez que a correção de tamanho aplicada aos dados (ver a seguir) uniformiza em grande parte a variância entre as variáveis.

Complementando a ACP, o dendrograma sobre distâncias de Mahalanobis permite inferir quanto às relações de afinidades biológicas entre as séries quando a totalidade da informação oferecida pelas variáveis incluídas é considerada. A distância de Mahalanobis consiste na diferença ao quadrado entre um par de séries para cada variável (similar à distância euclidiana), ponderando a contribuição de cada diferença pela covariância entre as variáveis (Mahalanobis, 1936). Desta forma, variáveis altamente correlacionadas contribuem relativamente menos para o valor final da distância entre as séries. Distâncias de Mahalanobis foram calculadas entre todos os pares de séries, sendo que a matriz de distâncias foi representada graficamente por meio de dendrograma utilizando o algoritmo de Ward. O algoritmo de Ward determina a união das séries em grupos, minimizando a variância interna aos grupos, ao mesmo tempo em que maximiza a variância entre grupos (Ward, 1963). O algoritmo de Ward maximiza a formação de grupos, gerando dendrogramas mais estruturados em comparação a outros métodos, o que tende a produzir resultados mais claros em análises morfológicas de grupos humanos modernos

Os nomes das variáveis craniométricas foram mantidos em inglês porque são assim universalmente conhecidos.

5 Ver Hubbe et al. (2011) para maiores detalhes.

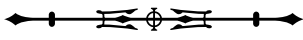




\begin{tabular}{|c|c|c|c|c|c|c|c|}
\hline 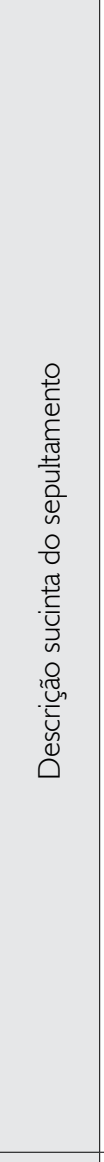 & 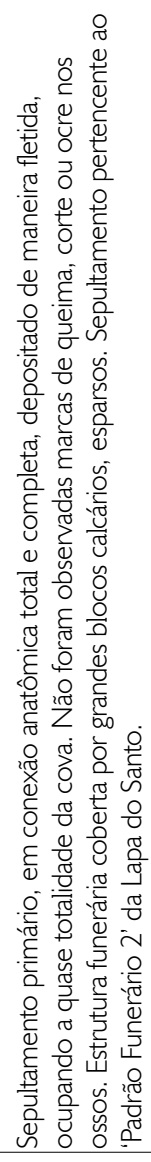 & 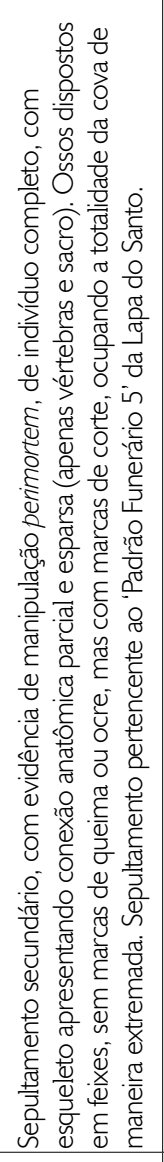 & 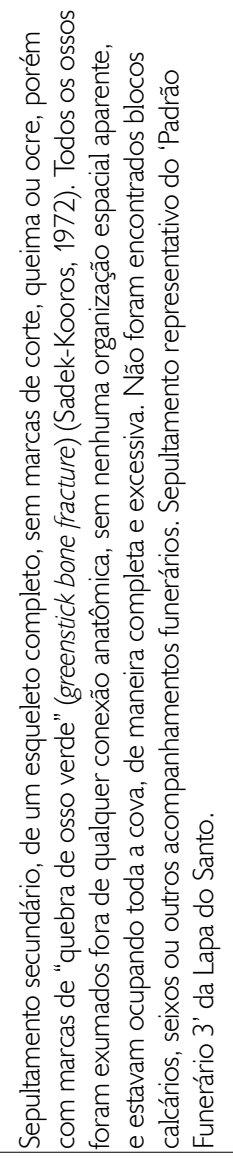 & 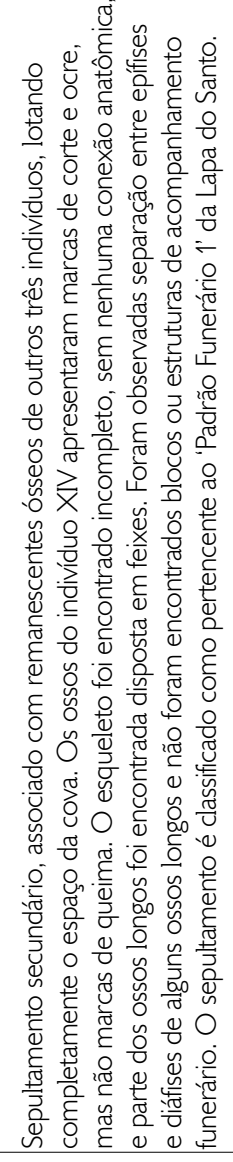 & 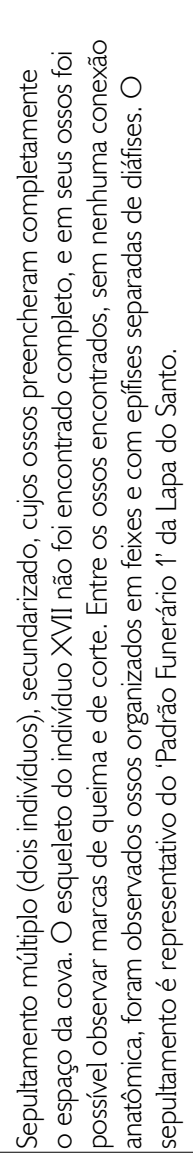 & 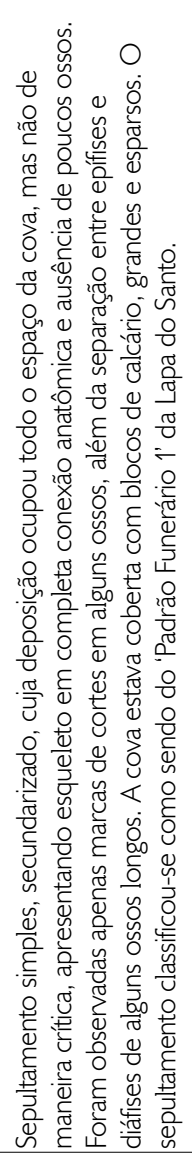 & 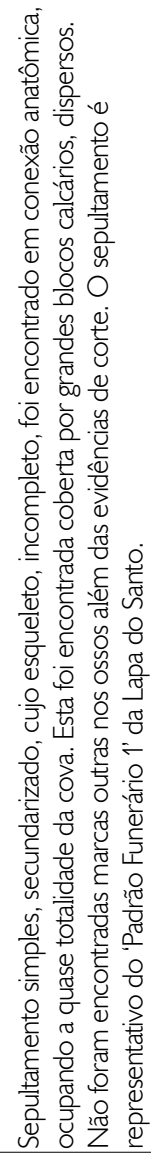 \\
\hline 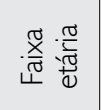 & $\frac{0}{\frac{0}{7}}$ & $\frac{0}{\frac{7}{7}}$ & $\begin{array}{l}\frac{9}{7} \\
\frac{7}{2} \\
\frac{0}{4}\end{array}$ & $\frac{0}{\frac{7}{7}}$ & $\frac{\text { 운 }}{\frac{7}{5}}$ & $\frac{0}{\frac{7}{7}}$ & $\frac{0}{\frac{0}{5}}$ \\
\hline 仓 & 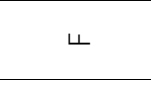 & ᄂ & $\Sigma$ & $\Sigma$ & $\Sigma$ & $\Sigma$ & $\Sigma$ \\
\hline 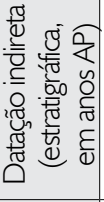 & ষ্ণ & 吉 & 8 & $\underset{\substack{\hat{\swarrow} \\
\text { N }}}{\widehat{N}}$ & 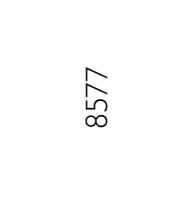 & $\underset{\substack{\text { } \\
\infty}}{\widehat{N}}$ & $\underset{\substack{\underset{\infty}{\infty} \\
\hat{n}}}{\widehat{N}}$ \\
\hline $\begin{array}{l}\frac{\pi}{0} \\
\infty \\
\text { \# }\end{array}$ & 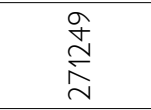 & 1 & & $\begin{array}{l}\frac{\sigma}{2} \\
\stackrel{\operatorname{in}}{N}\end{array}$ & $\begin{array}{l}\hat{\circ} \\
\stackrel{\leftrightarrow}{n} \\
\stackrel{\leftrightarrow}{n}\end{array}$ & & $\stackrel{\bar{i}}{\stackrel{\Sigma}{n}}$ \\
\hline 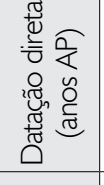 & $\begin{array}{l}8 \\
+1 \\
+ \\
\circ \\
\infty \\
\infty\end{array}$ & I & & $\begin{array}{l}\stackrel{\circ}{n} \\
+1 \\
\stackrel{\circ}{\infty} \\
\stackrel{\infty}{\infty}\end{array}$ & $\begin{array}{l}\circ \\
\text { ధn } \\
+1 \\
\circ \\
\varnothing \\
\varnothing \\
\infty\end{array}$ & & $\begin{array}{l}\text { 유 } \\
+1 \\
\text { 운 } \\
\text { ஸे }\end{array}$ \\
\hline 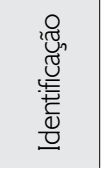 & 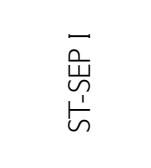 & $\begin{array}{l}\stackrel{0}{W} \\
\stackrel{1}{n}\end{array}$ & 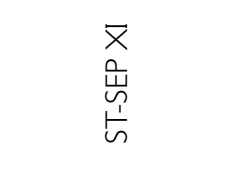 & 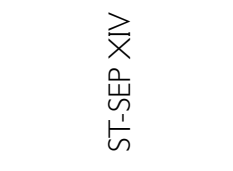 & 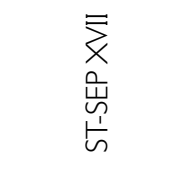 & $\begin{array}{l}\bar{x} \\
x \\
\stackrel{u}{u} \\
\stackrel{1}{n}\end{array}$ & 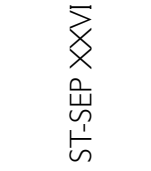 \\
\hline
\end{tabular}


Tabela 2. Identificação, abreviatura, localização geográfica, caracterização cronológica e tamanho amostral das séries de referência utilizadas neste estudo. Informações em negrito referem-se às séries Cerca Grande e Sumidouro, consideradas conjuntamente como Lagoa Santa.

\begin{tabular}{|c|c|c|c|c|c|c|}
\hline \multirow{2}{*}{ Série } & \multirow{2}{*}{ Abreviatura } & \multirow{2}{*}{ Localização } & \multirow{2}{*}{ Cronologia } & \multicolumn{3}{|c|}{ Número amostral } \\
\hline & & & & Masculino & Feminino & Total \\
\hline Cerca Grande & LAGOA & América do Sul & Holoceno inicial & 2 & 3 & 5 \\
\hline Sumidouro & LAGOA & América do Sul & Holoceno inicial & 9 & 4 & 13 \\
\hline Colômbia & $\mathrm{COL}$ & América do Sul & Holoceno inicial/médio & 23 & 31 & 54 \\
\hline Arikara & ARIK & América do Norte & Holoceno tardio/sub-recente & 42 & 27 & 69 \\
\hline Peru & PERU & América do Sul & Holoceno tardio/sub-recente & 55 & 55 & 110 \\
\hline Santa Cruz & SCRU & América do Norte & Holoceno tardio/sub-recente & 51 & 51 & 102 \\
\hline Berg & BERG & Europa & Holoceno tardio/sub-recente & 56 & 53 & 109 \\
\hline Norse & NORS & Europa & Holoceno tardio/sub-recente & 55 & 55 & 110 \\
\hline Zalavar & ZALA & Europa & Holoceno tardio/sub-recente & 53 & 45 & 98 \\
\hline Easter Island & EASTER ISLAND & Polinésia & Holoceno tardio/sub-recente & 49 & 37 & 86 \\
\hline Mokapu & MOKAPU & Polinésia & Holoceno tardio/sub-recente & 51 & 49 & 100 \\
\hline Moriori & MORIORI & Polinésia & Holoceno tardio/sub-recente & 57 & 51 & 108 \\
\hline Atayal & ATAYAL & Ásia & Holoceno tardio/sub-recente & 29 & 18 & 47 \\
\hline Buriat & BURI & Ásia & Holoceno tardio/sub-recente & 55 & 54 & 109 \\
\hline Hainan & HAIN & Ásia & Holoceno tardio/sub-recente & 45 & 38 & 83 \\
\hline Norte do Japão & $\mathrm{NOJP}$ & Ásia & Holoceno tardio/sub-recente & 55 & 32 & 87 \\
\hline Sul do Japão & $\mathrm{SOJP}$ & Ásia & Holoceno tardio/sub-recente & 50 & 41 & 91 \\
\hline Austrália & AUST & Australo-melanésia & Holoceno tardio/sub-recente & 52 & 49 & 101 \\
\hline Tasmânia & TASM & Australo-melanésia & Holoceno tardio/sub-recente & 45 & 42 & 87 \\
\hline Tolai & TOLA & Australo-melanésia & Holoceno tardio/sub-recente & 56 & 54 & 110 \\
\hline Bushman & $\mathrm{BUSH}$ & África & Holoceno tardio/sub-recente & 41 & 49 & 90 \\
\hline Dogon & DOGO & África & Holoceno tardio/sub-recente & 47 & 52 & 99 \\
\hline Teita & TEIT & África & Holoceno tardio/sub-recente & 33 & 50 & 83 \\
\hline Zulu & ZULU & África & Holoceno tardio/sub-recente & 55 & 46 & 101 \\
\hline Total & & & & 1.066 & 986 & 2.052 \\
\hline
\end{tabular}

(Okumura, 2008). A validade de cada agrupamento no dendrograma foi estimada por meio de mil bootstraps dos dados, e a probabilidade associada a cada agrupamento foi calculada como a frequência de vezes em que os dados permutados geraram os mesmos agrupamentos, dividido pelo total de permutações realizadas (mil, neste caso).

Devido à exiguidade das amostras de origem arqueológica, ambos os sexos foram analisados conjuntamente. Assim, previamente às análises, o efeito de dimorfismo sexual e tamanho dos crânios foi corrigido por intermédio da estandardização dos dados via escores z. Inicialmente, os escores z foram calculados para cada variável, considerando cada indivíduo de cada sexo separadamente. Em seguida, os dados foram agrupados, e um segundo escore z foi calculado para cada indivíduo, removendo efetivamente diferenças causadas por dimorfismo sexual ou tamanho dos crânios (Relethford, 1994). Todas as análises foram realizadas em R (R Development Core Team, 2010). 


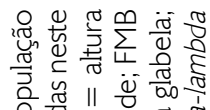

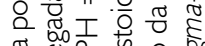

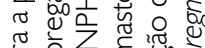
范 है

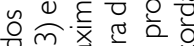

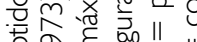

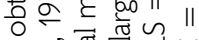

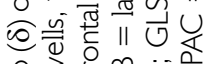

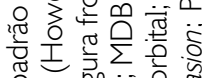

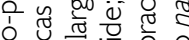

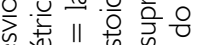

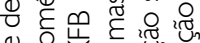
定.

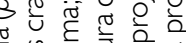

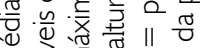
的

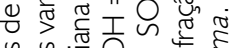

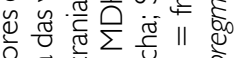

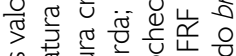

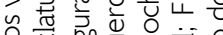
等

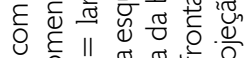

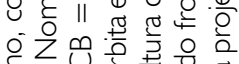

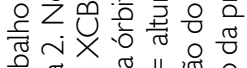

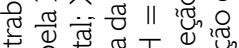

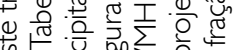

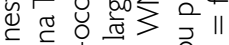
势

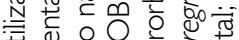
年

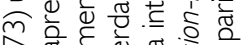

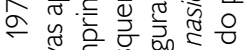

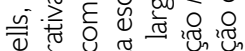

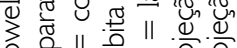

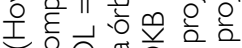
ชु

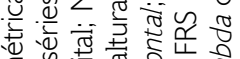

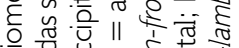

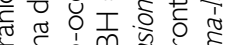

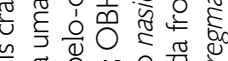
政

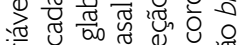

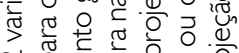

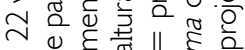

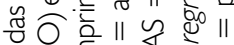
을

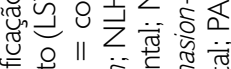

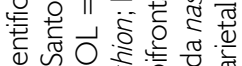

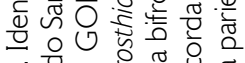
m

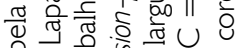

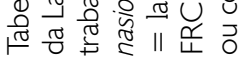

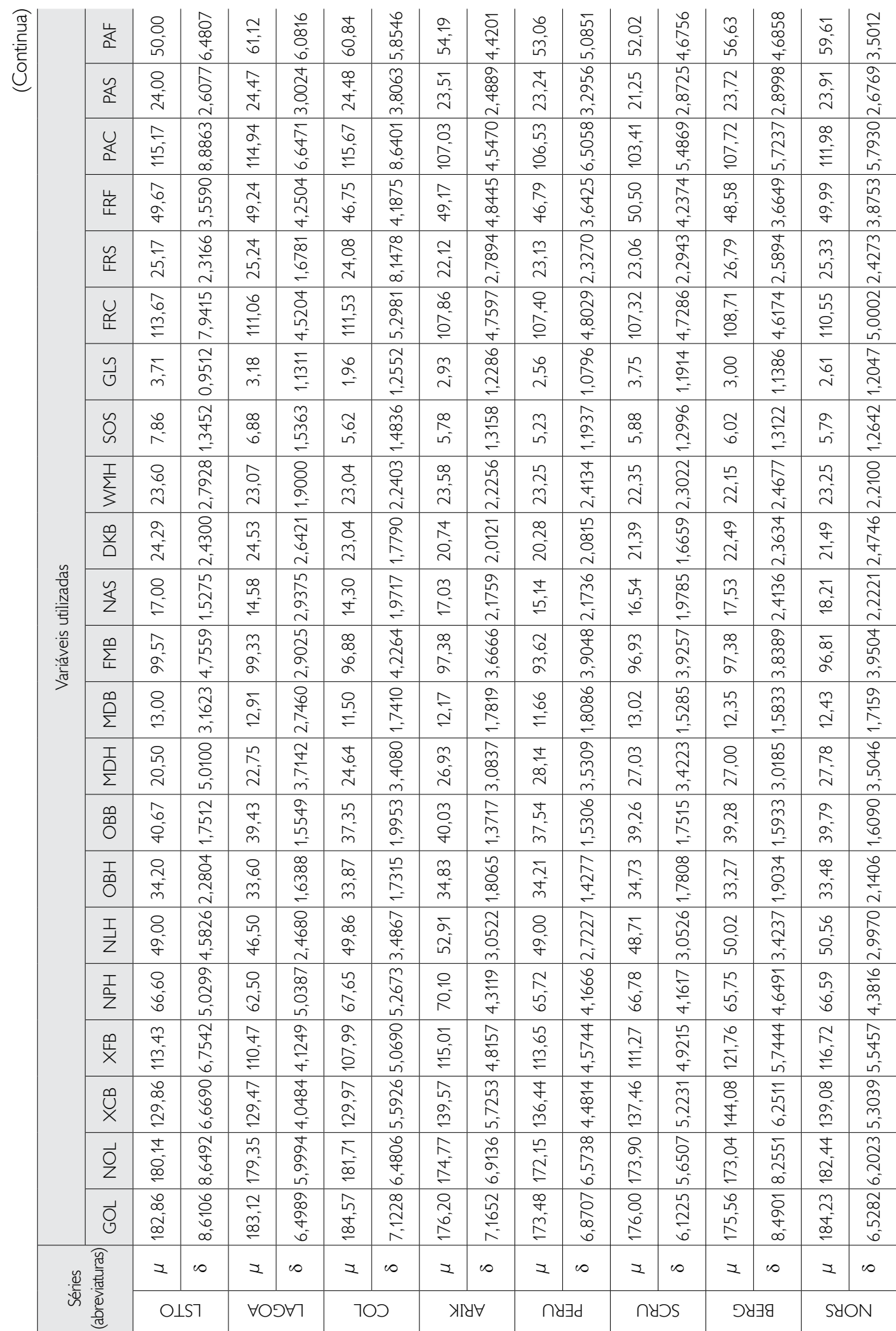




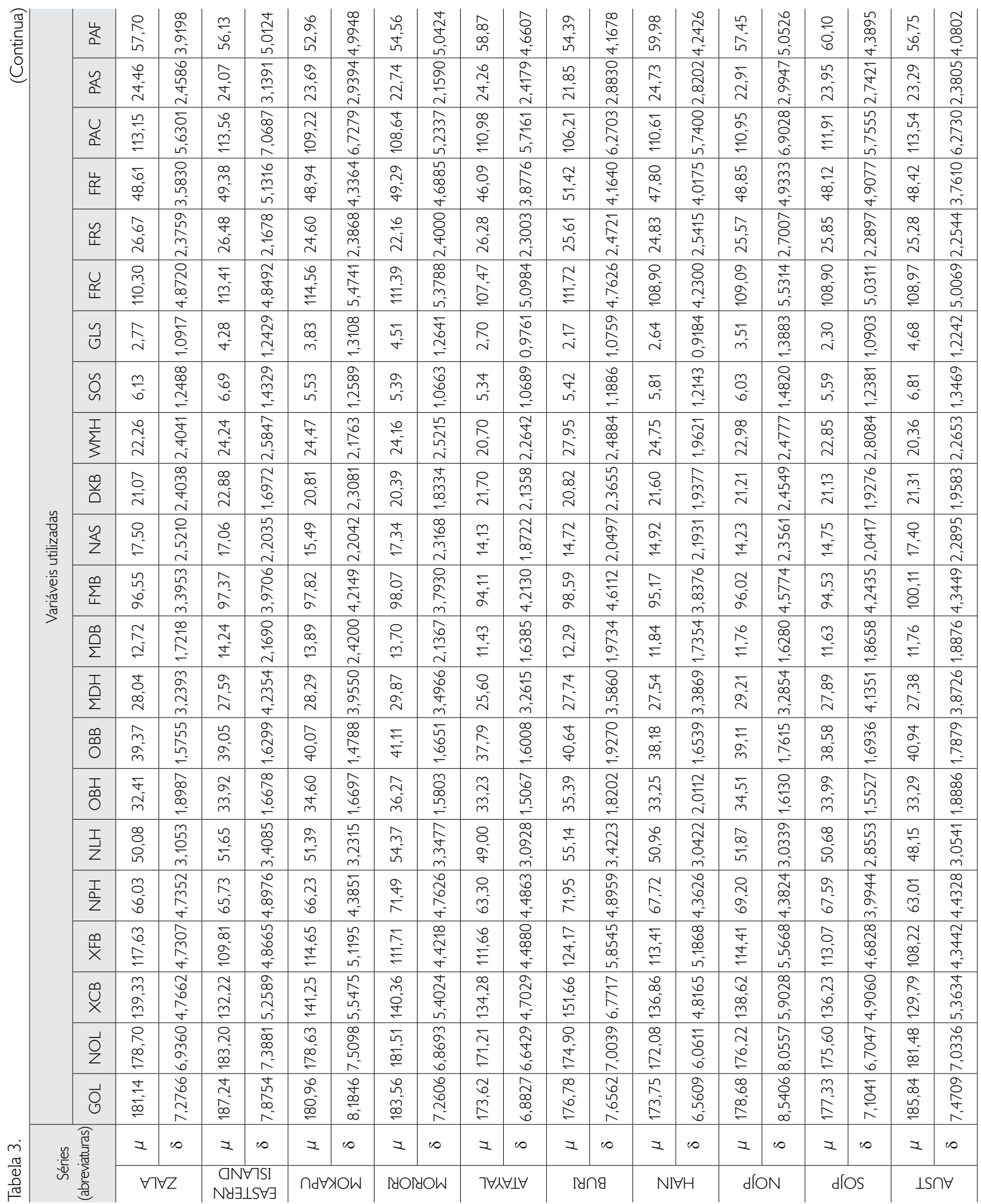




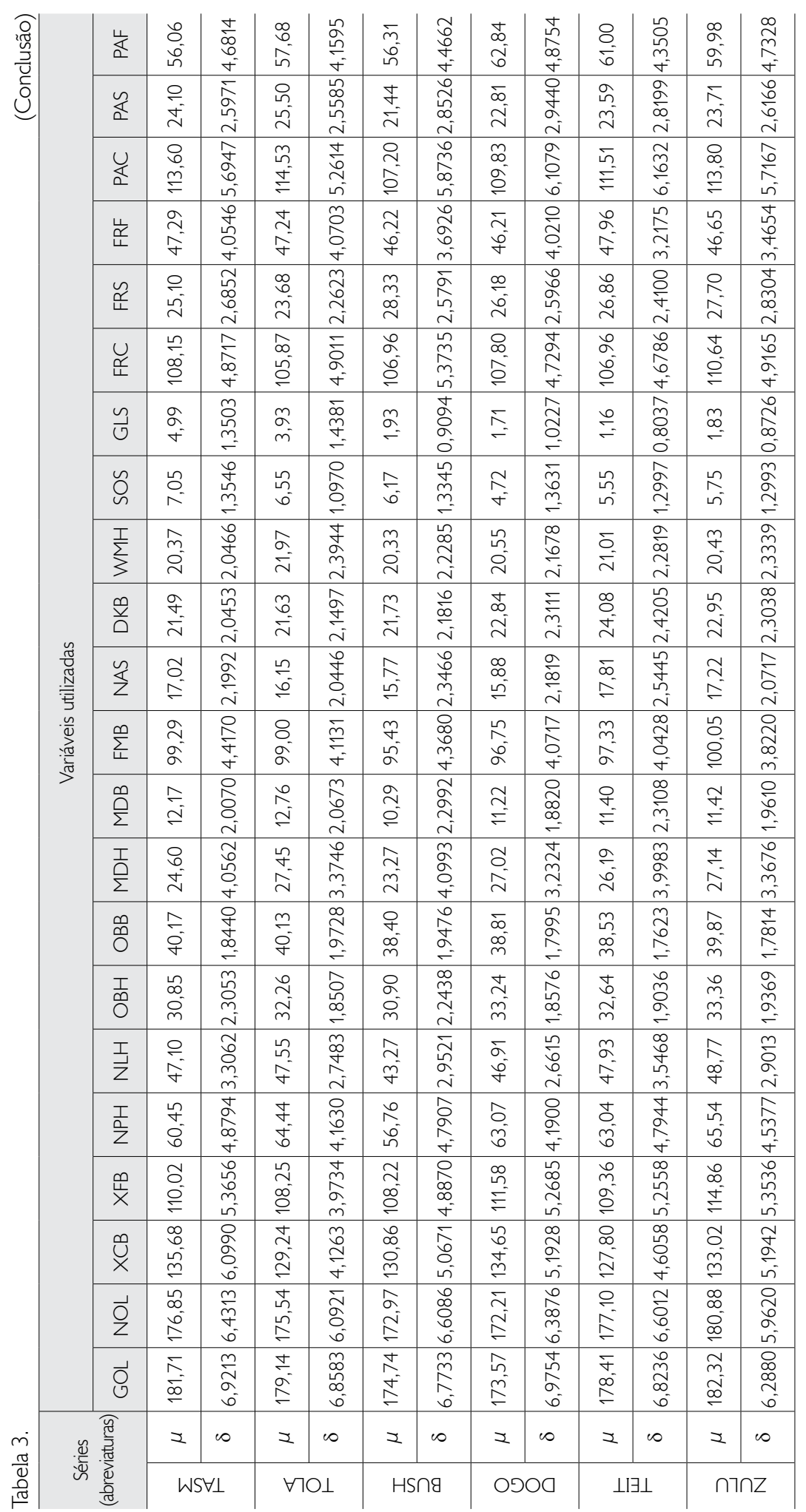




\section{RESULTADOS}

A Tabela 4 apresenta os valores médios de Coeficientes de Variação calculados para cada série. Como é possível de ser observado, as séries de Lagoa Santa, quando consideradas separadamente ou em conjunto, não apresentam CV fora dos limites observados para as séries de referência. Os crânios da Lapa do Santo, apesar de representarem quase três mil anos de ocupação humana e pelo menos duas tradições funerárias distintas, apresentam um CV médio de $10,3 \%$, encontrando-se dentro dos valores esperados para grupos recentes, o que favorece a interpretação de que o sítio representa uma única população biológica.

As Figuras 7 e 8 mostram os resultados das análises de afinidades biológicas entre as séries. A Figura 7 mostra a posição das séries no morfoespaço delimitado pelos dois primeiros componentes principais, que, em conjunto, resumem 29,1\% da variância total contida no banco de dados. Nesta análise, as séries de Lagoa Santa aparecem próximas a grupos australo-melanésios, africanos subsaarianos e da ilha de Páscoa (Easter Island). Lapa do Santo, em particular, mostra uma maior afinidade com grupos australo-melanésios do que os demais grupos antigos da América do Sul. Grupos nativos americanos recentes, por outro lado, aparecem no extremo oposto do gráfico, associados com grupos do leste asiático e demais grupos polinésios. A Figura 7 também apresenta as variáveis craniométricas com as maiores correlações com cada componente principal (CP). Como pode ser observado, grupos com valores baixos no primeiro CP, como Lapa do Santo, Lagoa Santa e Colômbia, possuem neurocrânios longos (+GOL, +PAC, +PAS, +PAF) e faces e narizes baixos (-OBH, -WMH, -NPH, -NLH). A diferença entre Lapa do Santo e as séries Lagoa Santa e Colômbia, neste gráfico, se dá basicamente pelo fato de que, na primeira, o comprimento do parietal contribui relativamente menos para o comprimento do crânio, enquanto que, em Lagoa Santa e Colômbia, os crânios longos se devem principalmente ao maior comprimento do parietal. As séries americanas recentes apresentam um padrão morfológico oposto ao de Lagoa Santa, com neurocrânios curtos (-GOL, -PAC, -PAF, -PAS) e faces e narizes altos $(+\mathrm{OBH},+\mathrm{WMH},+\mathrm{NPH},+\mathrm{NLH})$.

O dendrograma ilustrado na Figura 8 apoia completamente os resultados apresentados pela ACP. Os grupos antigos da América do Sul aparecem associados em um agrupamento com australo-melanésios e ilha de Páscoa. Este grupo é bastante estável, tendo ocorrido em $96 \%$ das 1.000 permutações realizadas pelo bootstrap. A associação observada entre Lapa do Santo e o grupo que contém Lagoa Santa, Colômbia e ilha de Páscoa apresenta menor nível de suporte $(p=0,68)$, porém isso pode ocorrer devido ao baixo número de indivíduos nas amostras sul-americanas, em particular no caso da Lapa do Santo. Os grupos americanos recentes (Peru, Arikara e Santa Cruz) aparecem associados a grupos polinésios, em um agrupamento com alto nível de suporte ( $p=0,96)$, confirmando a informação observada na análise anterior, de que os grupos tardios do continente apresentam morfologia bastante distinta dos grupos antigos.

\section{DISCUSSÃO E CONCLUSÕES}

Os resultados obtidos neste trabalho apoiam estudos anteriores (Neves e Hubbe, 2005; Neves et al., 2004, 2007b, 2007c, 2013; Bernardo, 2007; Bernardo e Neves, 2009; Hubbe et al., 2010, 2011; Bernardo et al., 2011), que mostram uma grande afinidade morfológica entre os grupos de Lagoa Santa e séries australo-melanésias, e, em segundo lugar, com os povos africanos representados nas séries Howells. Em contraparte, os crânios de populações nativas americanas recentes (Arikara, Santa Cruz e Peru) ocupam uma posição completamente oposta no morfoespaço, agrupando-se com populações da Ásia, da Polinésia e da Europa, à exceção dos habitantes tardios da ilha de Páscoa, que mostram maior afinidade ao material de Lagoa Santa.

Além de confirmarem os resultados antigos, as análises também sugerem que, apesar de representarem quase três mil anos de ocupação humana, os crânios de Lagoa Santa possuem níveis de diversidade biológica coerentes com uma

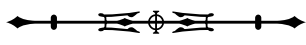


Tabela 4. Valores médios dos coeficientes de variação de cada uma das séries utilizadas neste estudo. Legenda: * = série mista, composta pelas séries Cerca Grande e Sumidouro.

\begin{tabular}{|c|c|c|}
\hline Série & Filiação geográfico-cronológica & Coeficiente médio de variação \\
\hline Lapa do Santo & Paleoíndios de Lagoa Santa & 0,102684 \\
\hline Cerca Grande & Paleoíndios de Lagoa Santa & 0,098621 \\
\hline Sumidouro & Paleoíndios de Lagoa Santa & 0,095715 \\
\hline Lagoa Santa & Paleoíndios de Lagoa Santa* & 0,101690 \\
\hline Colômbia & Paleoíndios da Colômbia & 0,109422 \\
\hline Arikara & Nativos americanos recentes/sub-recentes & 0,096913 \\
\hline Peru & Nativos americanos recentes/sub-recentes & 0,099821 \\
\hline Santa Cruz & Nativos americanos recentes/sub-recentes & 0,090625 \\
\hline Berg & Nativos europeus recentes/sub-recentes & 0,096703 \\
\hline Norse & Nativos europeus recentes/sub-recentes & 0,097402 \\
\hline Zalavar & Nativos europeus recentes/sub-recentes & 0,093703 \\
\hline Easter Island & Nativos polinésios recentes/sub-recentes & 0,094076 \\
\hline Mokapu & Nativos polinésios recentes/sub-recentes & 0,098547 \\
\hline Moriori & Nativos polinésios recentes/sub-recentes & 0,089671 \\
\hline Atayal & Nativos asiáticos recentes/sub-recentes & 0,092824 \\
\hline Buriat & Nativos asiáticos recentes/sub-recentes & 0,103563 \\
\hline Hainan & Nativos asiáticos recentes/sub-recentes & 0,092124 \\
\hline Norte do Japão & Nativos asiáticos recentes/sub-recentes & 0,102688 \\
\hline Sul do Japão & Nativos asiáticos recentes/sub-recentes & 0,101761 \\
\hline Austrália & Nativos austral-melanésios recentes/sub-recentes & 0,089821 \\
\hline Tasmânia & Nativos austral-melanésios recentes/sub-recentes & 0,094529 \\
\hline Tolai & Nativos austral-melanésios recentes/sub-recentes & 0,091451 \\
\hline Bushman & Nativos africanos recentes/sub-recentes & 0,109824 \\
\hline Dogon & Nativos africanos recentes/sub-recentes & 0,111019 \\
\hline Teita & Nativos africanos recentes/sub-recentes & 0,115373 \\
\hline Zulu & Nativos africanos recentes/sub-recentes & 0,100737 \\
\hline
\end{tabular}

única população humana moderna. Em outras palavras, os resultados apresentados favorecem a ideia de que, pelo menos do ponto de vista morfológico, os grupos de Lagoa Santa representam uma única população.

Tais resultados não são de todo surpreendentes, se for considerado que a morfologia que caracteriza grupos antigos nas Américas (morfologia paleoamericana) é encontrada virtualmente em todos os crânios mais antigos do que sete mil anos AP no continente (Neves et al., 1999, 2005, 2007b, 2007c; Hubbe et al., 2004, 2007; González-José et al., 2005). De fato, tal morfologia parece ser uma retenção da que caracterizava grupos humanos ao final do Pleistoceno em grande parte do planeta (Hubbe et al., 2011).

A morfologia peculiar dos grupos antigos de Lagoa Santa e sua presença por todo o continente

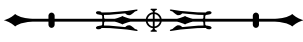




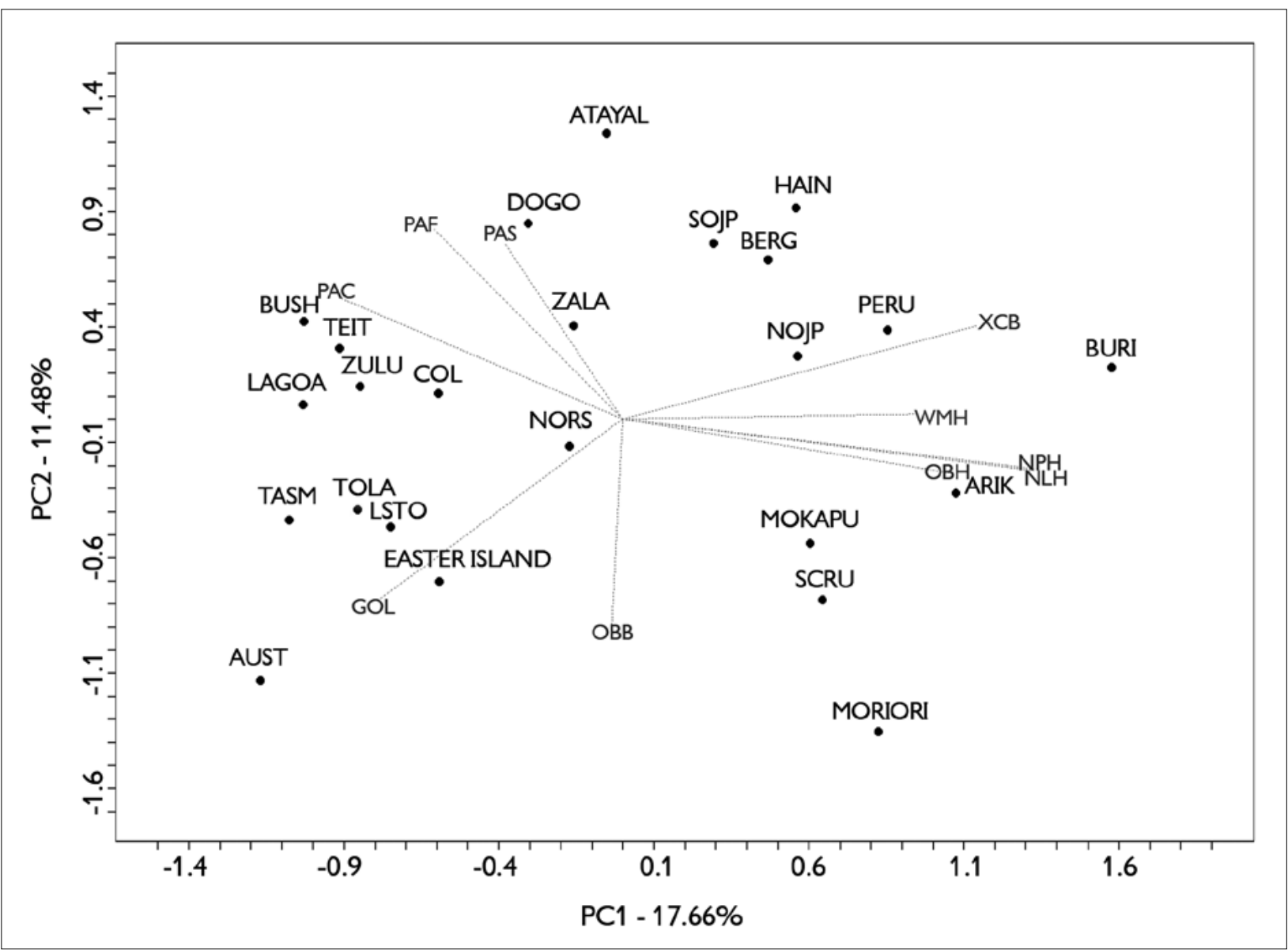

Figura 7. Dispersão no morfoespaço formado pelos dois primeiros componentes principais, baseada nos centroides das séries analisadas. Em cinza, destacam-se as variáveis que possuem correlações $(r)$ maiores que 0,5 , representando as variáveis que mais influenciam em cada um dos componentes principais ilustrados.

sugerem que a dispersão inicial de grupos humanos pelo continente americano foi complexa e envolveu uma forte mudança morfológica durante o Holoceno. Grosso modo, três modelos foram propostos para explicar os processos que deram origem a esta mudança morfológica no continente.

O primeiro defende que a transição morfológica se deu inteiramente por processos microevolutivos locais, com grupos de morfologia paleoamericana gradativamente desenvolvendo a morfologia que caracteriza grande parte dos grupos nativos americanos atuais (Powell, 2005). Tal modelo é apoiado pela maioria dos estudos moleculares atuais, que defende uma origem única para todos os grupos nativos americanos (por exemplo, Bonatto e Salzano, 1997; Zegura et al., 2004; Tamm et al., 2007; Wang et al., 2007; Fagundes et al., 2008a, 2008b), ainda que estudos mais recentes defendam duas (Perego et al., 2009) ou três (Reich et al., 2012) migrações discretas para o continente. Neste quadro, as mudanças morfológicas observadas na América do Sul durante o Holoceno seriam o produto de processos evolutivos neutros (deriva e fluxo gênico; Powell, 2005), ou seleção natural a novas demandas associadas a estilos de vida distintos (por exemplo, adoção da agricultura; Perez et al., 2009). 


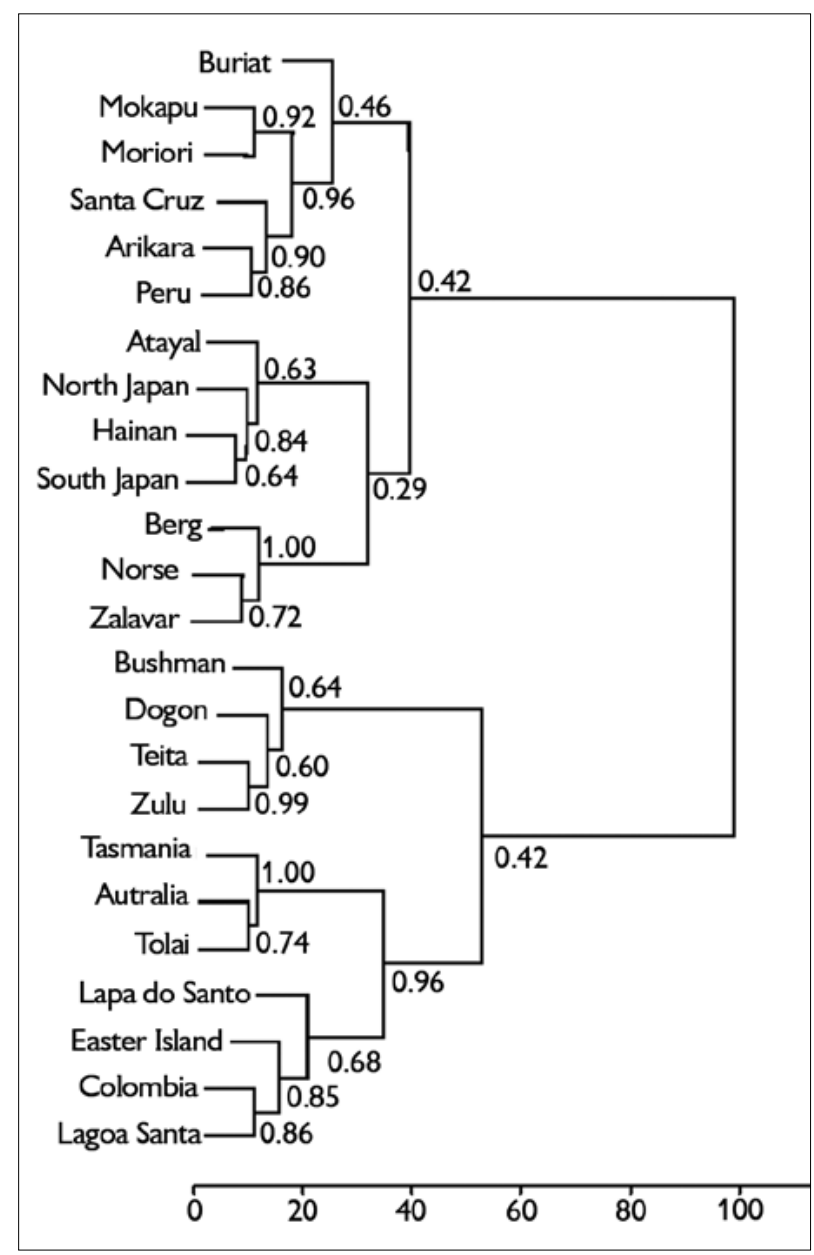

Figura 8. Dendrograma gerado a partir do método Ward, sobre a matriz de distâncias de Mahalanobis entre as séries analisadas. Os valores apresentados em cada agrupamento representam as frequências de ocorrência de cada agrupamento de acordo com 1.000 bootstraps das séries.

Os outros modelos, por sua vez, defendem que a diversidade morfológica no continente é muito alta para ser explicada somente por processos evolutivos locais. O segundo modelo defende que a morfologia paleoamericana e a morfologia recente (denominada aqui de ameríndia) representam fluxos migratórios distintos para dentro do continente (Neves e Hubbe, 2005; Hubbe et al., 2010). Este modelo argumenta, portanto, que a primeira onda migratória para o continente foi composta por grupos humanos com morfologia paleoamericana.
A morfologia ameríndia teria sido introduzida em um segundo fluxo migratório e, em algumas regiões do continente, também teria substituído ou se miscigenado com os grupos paleoamericanos.

Finalmente, o terceiro modelo nasceu de um esforço em tentar compatibilizar os dados morfológicos com os moleculares (González-José et al., 2008). Tal modelo assume que, apesar de a diversidade morfológica no continente não poder ser explicada inteiramente por processos evolutivos locais, o influxo de diversidade biológica não esteve estruturado em fluxos migratórios discretos, mas seria o produto de fluxo ou intercâmbio genético contínuo com o noroeste asiático (González-José et al., 2008; Azevedo et al., 2011).

Ainda que o presente estudo não tenha sido desenhado para testar qual modelo melhor explica as diferenças morfológicas aqui observadas, nossos resultados parecem dar maior sustentação aos modelos que assumem a contribuição externa de diversidade biológica durante o Holoceno. $O$ fato é que, quando se confrontam as séries esqueletais de grande antiguidade com as séries recentes, dois conjuntos associativos bastante discretos se formam: um claramente associado com grupos australo-melanésios (com morfologia similar à do final do Pleistoceno no planeta), composto pelos crânios de Lagoa Santa e da Colômbia; e outro com maior afinidade a grupos do leste asiático (e parte dos grupos polinésios, no caso deste estudo).

Não só não foram observados grupos de morfologia intermediária em nossas análises, como as diferenças morfológicas observadas na América ao longo do tempo representam extremos opostos da diversidade morfológica dos grupos humanos modernos no planeta como um todo. Em outras palavras, observamos a mesma magnitude de diferenças morfológicas dentro do continente americano que a observada entre os grupos humanos modernos mais distintos entre si. Desta forma, é difícil sustentar que as mudanças morfológicas observadas no continente se devam à seleção natural e a mudanças de estilo de vida associadas à adoção da agricultura, como sugerido por 
Perez et al. (2009). De maneira similar, a remoção de dimensões cranianas que respondem adaptativamente ao clima não diminui as diferenças entre grupos antigos e recentes no planeta (Hubbe et al., 2010), refutando a hipótese de que seleção natural a mudanças climáticas seja uma das forças geradoras de tais diferenças.

Por outro lado, com os resultados apresentados aqui, é difícil discernir entre um modelo de dois fluxos migratórios distintos e um modelo de fluxo contínuo com a Ásia, dado que os dois produziriam resultados similares aos observados. Seria necessário incluir um número significativo de séries cronologicamente intermediárias para poder testar essas alternativas de maneira adequada.

De qualquer forma, deve ser destacado que as discussões e conclusões apresentadas neste trabalho emergem quando a América do Sul é investigada. Por mais que exista uma tendência em generalizar as conclusões obtidas com o material da América do Sul para o resto do Novo Mundo, é possível, se não provável, que os processos de dispersão humana pelo continente sul-americano tenham tido características e dinâmicas próprias, distintas do que haveria ocorrido no hemisfério norte. Estudos arqueológicos parecem concordar com essa ideia, dado que tradições culturais norte-americanas (como Clovis, por exemplo), não estão presentes na América do Sul, e viceversa (Dillehay, 2000). Neste contexto, é importante ressaltar que estudos futuros na América do Norte, quando coleções esqueletais antigas forem ali encontradas, poderão trazer novas luzes sobre a questão da origem da diversidade biológica de grupos nativos americanos no passado.

Em conclusão, os resultados apresentados aqui sugerem que os primeiros habitantes de Lagoa Santa (e do sub-continente como um todo) compartilharam as mesmas características morfológicas e provavelmente pertenciam a um mesmo grupo biológico. As mudanças culturais observadas em Lagoa Santa por volta de 8000 anos AP, portanto, não teriam envolvido a chegada de novas populações biológicas na região. Por outro lado, em algum momento durante o Holoceno Médio surgiu um novo padrão morfológico no continente, que provavelmente resultou do influxo de uma nova população biológica nas Américas. Em algumas partes do continente, esta nova morfologia substituiu grupos com morfologia paleoamericana, mas, em outras, a morfologia antiga parece ter sobrevivido até momentos recentes (GonzálezJosé et al., 2003; Lahr, 1995; Atuí, 2005; Bernardo et al., 2011). De especial interesse no contexto de Lagoa Santa é a situação observada no território brasileiro, onde grupos costeiros apresentam a morfologia ameríndia durante o Holoceno Médio (Okumura, 2008). Porém, grupos nos planaltos do centro-leste brasileiro parecem ter retido a morfologia paleoamericana até o período colonial (Atuí, 2005; Bernardo et al., 2011).

Entre os grupos que parecem reter a morfologia paleoamericana, estão os índios Botocudos do centroleste brasileiro (Bernardo et al., 2011). Recentemente, Gonçalves et al. (2013) descreveram que alguns destes indivíduos possuem linhagens de DNA mitocondrial únicas no continente. A possível origem de tais linhagens foi identificada como a Polinésia ou o leste africano. A origem no leste africano poderia indicar que os índios analisados se miscigenaram com escravos africanos durante o período colonial brasileiro. Porém, a origem polinésia, se confirmada, indicaria um novo aspecto de complexidade no que se refere à diversidade biológica sul-americana, dado que uma conexão entre Polinésia e leste do continente americano é difícil de explicar. Ainda assim, cabe mencionar que, nas análises apresentadas aqui, a série da ilha de Páscoa apresenta grande afinidade morfológica com grupos antigos do continente americano. Estudos mais abrangentes sobre a diversidade biológica e craniométrica de grupos nativos americanos serão necessários para iluminar esta questão.

\section{AGRADECIMENTOS}

Este trabalho foi possível graças ao financiamento da Fundação de Amparo à Pesquisa do Estado de São Paulo (FAPESP) (Processos 99/0191-8 e 04/01321-6 para WAN e 08/58729-8 para DVB), Conselho Nacional de Desenvolvimento Científico e Tecnológico (CNPq)

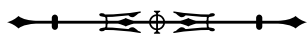


(Processo 300917/2010-4) e Max Planck Institute for Evolutionary Anthropology. Somos imensamente gratos a todos aqueles que durante a última década participaram do projeto "Origens e micro-evolução do Homem na América: uma abordagem Paleo-Antropológica". Ainda que muito numerosos para citar aqui, suas colaborações nas distintas fases do projeto foram fatores que permitiram, em última análise, a elaboração do presente artigo.

\section{REFERÊNCIAS}

ARAUJO, A. G. M. Síntese. In: ARAUJO, A. G. M; NEVES, W. A. (Eds.). Lapa das Boleiras: um sítio paleoíndio do Carste de Lagoa Santa, MG, Brasil. São Paulo: Editora Annablume/FAPESP, 2010. p. 213-219.

ARAUJO, A. G. M.; STRAUSS, A. M.; FEATHERS, J. K.; PAISANI, J. C.; SCHRAGE, T. J. Paleoindian open-air sites in tropical settings: a case study in formation processes, dating methods, and paleoenvironmental models in Central Brazil. Geoarchaeology, v. 28, n. 3, p. 195-220, 2013.

ARAUJO, A. G. M.; NEVES, W. A.; KIPNIS, R. Lagoa Santa revisited: an overview of the chronology, subsistence, and material culture of Paleoindian sites in Eastern Central Brazil. Latin American Antiquity, v. 23, n. 4, p. 533-550, 2012.

ARAUJO, A. G. M.; FEATHERS, J. K. First notice of open-air Paleoamerican sites at Lagoa Santa: some geomorphological and paleoenvironmental aspects and implications for future research. Current Research in the Pleistocene, v. 25, p. 27-29, 2008.

ARAUJO, A. G. M.; FEATHERS, J. K.; ARROYOU-KALIN, M.; TIZUKA, M. M. Lapa das Boleiras rockshelter: stratigraphy and formation processes at a Paleoamerican site in Central Brazil. Journal of Archaeological Science, v. 35, n. 12, p. 3186-3202, 2008.

ARAUJO, A. G. M.; NEVES, W.; PILÓ, L.; ATUÍ, J. P. V. Holocene dryness and human occupation in Brazil during the "Archaic Gap". Quaternary Research, v. 64, n. 3, p. 298-307, 2005.

ATUÍ, J. P. V. Morfologia craniana de ameríndios brasileiros recentes e suas implicações para a questão da ocupação do Novo Mundo: uma análise exploratória. 2005. 192 f. Dissertação (Mestrado em Genética) - Universidade de São Paulo, São Paulo, 2005.

AZEVEDO, S.; NOCERA, A.; PASCHETTA, C.; CASTILLO, L.; GONZÁLEZ, M.; GONZÁLEZ-JOSÉ, R. Evaluating microevolutionary models for the early settlement of the New World: the importance of recurrent gene flow with Asia. American Journal of Physical Anthropology, v. 146, n. 4, p. 539-552, 2011.

BERNARDO, D. V. Diversidade craniana humana e suas implicações evolutivas. 2012. 344 f. Tese (Doutorado em Genética e Biologia Evolutiva) - Universidade de São Paulo, São Paulo, 2012.
BERNARDO, D. V. Afinidades morfológicas intra e extracontinentais dos Paleoíndios de Lagoa Santa: uma nova abordagem. 2007. 333 f. Dissertação (Mestrado em Genética e Biologia Evolutiva) - Universidade de São Paulo, São Paulo, 2007.

BERNARDO, D. V.; NEVES, W. A.; STRAUSS, A.; ALMEIDA, T. F; DE OLIVEIRA, R. E. Cranial morphology of early human skeletal remains from Lapa do Santo, Lagoa Santa, Brazil: implications for the settlement of the New World. American Journal of Physical Anthropology, v. 147, n. S54, p. 98, 2012.

BERNARDO, D. V.; STRAUSS, A.; NEVES, W. A.; OKUMURA, M. Measuring skulls: getting into the biological realm of the settlement of the New World. In: VIALOU, D. (Ed.). Peuplements et préhistoire en Amériques. Paris: Comité des Travaux Historiques et Scientifiques, 2011. p. 31-42.

BERNARDO, D. V.; NEVES, W. A. Diversidade morfocraniana dos remanescentes ósseos humanos da Serra da Capivara: implicações para a origem do homem americano. FUMDHAMentos, v. 8, p. 95-106, 2009.

BONATTO, S. L.; SALZANO, F. M. A single and early migration for the peopling of the Americas supported by mitochondrial DNA sequence data. Proceedings of the National Academy of Sciences of the United States of America, v. 94, n. 5, p. 1866-1871, 1997.

DA-GLORIA, P. Health and lifestyle in the Paleoamericans: Early Holocene biocultural adaptation at Lagoa Santa, Central Brazil. 2012. 821 f. Tese (Doutorado em Antropologia) - The Ohio State University, Columbus, 2012.

DILLEHAY, T. D. The settlement of the Americas: a new prehistory. New York: Basic Books, 2000.

EDMONDSON, E. M. S. Food composition and food cariogenicity factors affecting the cariogenic potential of foods. Caries Research, v. 24, supl. 1, p. 60-71, 1990.

FAGUNDES, N. J. R.; KANITZ, R.; BONATTO, S. L. A reevaluation of the Native American mtDNA genome diversity and its bearing on the models of early colonization of Beringia. PLoS ONE, v. 3, n. 9, p. e3157, 2008a.

FAGUNDES, N. J. R.; KANITZ, R.; ECKERT, R.; VALLS, A. C. S.; BOGO, M. R.; SALZANO, F. M.; SMITH, D. G.; SILVA JR., W. A.; ZAGO, M. A.; RIBEIRO-DOS-SANTOS, A. K.; SANTOS, S. E. B.; PETZL-ERLER, M. L.; BONATTO, S. Mitochondrial population genomics supports a single pre-Clovis origin with a coastal route for the peopling of the Americas. American Journal of Human Genetics, v. 82, n. 3, p. 583-592, 2008b.

FEATHERS, J.; KIPNIS, R.; PILÓ, L.; ARROYO-KALIN, M.; COBLENTZ, D. How old is Luzia? Luminescence dating and stratigraphic integrity at Lapa Vermelha, Lagoa Santa, Brazil. Geoarchaeology, v. 25, n. 4, p. 395-436, 2010.

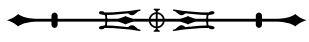


GONÇALVES, V. F.; STENDERUP, J.; RODRIGUES-CARVALHO, C.; SILVA, H. P.; GONÇALVES-DORNELAS, H.; LÍRYO, A.; KIVISILD, T.; MALASPINAS, A.; CAMPOS, P. F.; RASMUSSEN, M.; WILLERSLEV, E.; PENA, S. D. J. Identification of Polynesian $m t D N A$ haplogroups in remains of Botocudo Amerindians from Brazil. Proceedings of the National Academy of Sciences of the United States of America, v. 110, n. 16, p. 6465-6469, 2013

GONZÁLEZ-JOSÉ, R.; BORTOLINI, M. C.; SANTOS, F. R.; BONATTO, S. L. The peopling of America: craniofacial shape variation on a continental scale and its interpretation from an interdisciplinary view. American Journal of Physical Anthropology, v. 137, n. 2, p. 175-187, 2008.

GONZÁLEZ-JOSÉ, R.; NEVES, W. A.; LAHR, M. M.; GONZÁLEZ, S.; PUCCIARELLI, H. M.; MARTÍNEZ, M. H.; CORREAL, U. Late Pleistocene/Holocene craniofacial morphology in Mesoamerican Paleoindians: implications for the peopling of the New World. American Journal of Physical Anthropology, v. 128, n. 4, p. 772780, 2005.

GONZÁLEZ-JOSÉ, R.; GONZÁLEZ-MARTÍN, A.; HERNÁNDEZ, M.; PUCCIARELLI, H. M.; SARDI, M.; ROSALES, A. S.; VAN DER MOLEN, S. Craniometric evidence for Palaeoamerican survival in Baja California. Nature, v. 425, p. 62-65, 2003.

HAIR JR., J. F.; ANDERSON, R. E.; TATHAM, R. L.; BLACK, W. C. Análise multivariada de dados. 5. ed. Porto Alegre: Bookman, 2005.

HANIHARA, T. Comparison of craniofacial features of major human groups. American Journal of Physical Anthropology, v. 99, n. 3, p. 389-412, 1996.

HANSEN, S. Lagoa Santa Racen. In: LÜTKEN, C. F. (Org.). E Museo Lundii. Copenhagen: H. Hagerup, 1888. v. 1, p. 1-37.

HOWELLS, W. W. Who's who in skulls: ethnic identification of crania from measurements. Cambridge: Harvard University Press, 1999. (Papers of the Peabody Museum of Archaeology and Ethnology, v. 82).

HOWELLS, W. W. Skull shapes and the map. Craniometric analyses in the dispersion of modern Homo. Cambridge: Harvard University Press, 1989. (Papers of the Peabody Museum of Archaeology and Ethnology, v. 79).

HOWELLS, W. W. Cranial variation in Man. A study by multivariate analysis of patterns of difference among recent human populations. Cambridge: Harvard University Press, 1973. (Papers of the Peabody Museum of Archaeology and Ethnology, v. 67).

HRDLICKA, A. Early Man in South America. Washington: Smithsonian Institution, 1912. (Bureau of American Ethnology Bulletin, v. 52).

HUBBE, A.; HUBBE, M.; NEVES, W. A. The Brazilian megamastofauna of the Pleistocene/Holocene transition and its relationship with the early human settlement of the continent. Earth-Science Reviews, v. 118, p. 1-10, 2013.
HUBBE, A.; HADDAD-MARTIM, P. M.; HUBBE, M.; NEVES, W. A. Comments on: "An anthropogenic modification in an Eremotherium tooth from northeastern Brazil". Quaternary International, v. 269, p. 94-96, 2012.

HUBBE, A.; HUBBE, M; NEVES, W. New Late-Pleistocene dates for the extinct megafauna of Lagoa Santa, Brazil. Current Research in the Pleistocene, v. 26, p. 154-156, 2009.

HUBBE, M.; HARVATI, K.; NEVES, W. Paleoamerican morphology in the context of European and East Asian Late Pleistocene variation: implications for human dispersion into the New World. American Journal of Physical Anthropology, v. 144, n. 3, p. 442-453, 2011.

HUBBE, M.; NEVES, W. A.; HARVATI, K. Testing evolutionary and dispersion scenarios for the settlement of the New World. PLoS ONE, v. 5, n. 6, p. e11105, 2010.

HUBBE, M.; NEVES, W. A.; DO AMARAL, H. L.; GUIDON, N. "Zuzu" strikes again: morphological affinities of the early Holocene human skeleton from Toca dos Coqueiros, Piauí, Brazil. American Journal of Physical Anthropology, v. 134, n. 2, p. 285-291, 2007.

HUBBE, M.; NEVES, W. A.; ATUÍ, J. P. V.; CARTELLE, C.; SILVA, M. $P$. A new early human skeleton from Brazil: support for the "two main biological components model" for the settlement of the Americas. Current Research in the Pleistocene, v. 21, p. 77-81, 2004.

HURT, W. R.; BLASI, O. O projeto arqueológico Lagoa Santa, Minas Gerais, Brasil. Arquivos do Museu Paranaense (N. S.) Arqueologia, v. 4, p. 1-63, 1969.

JANTZ, R. L.; OWSLEY, D. W. Variation among early North America crania. American Journal of Physical Anthropology, v. 114, n. 2, p. 146-155, 2001.

KOLLMANN, J. Schädeln von Lagoa Santa. Zeitschrift für Ethnologie, v. 16, p. 194-199, 1884.

LACERDA, J. B.; PEIXOTO, R. Contribuições para o estudo anthropológico das raças indígenas do Brazil. Archivos do Museu Nacional do Rio de Janeiro, v. 1, p. 47-75, 1876.

LAHR, M. M. Patterns of modern human diversification: implications for Amerindians origins. American Journal of Physical Anthropology, v. 38, supl. S2, p. 163-198, 1995

LAMING-EMPERAIRE, A. Missions archéologique francobrésiliennes en Lagoa Santa, Minas Gerais, Brésil: le grand abri de Lapa Vermelha. Revista de Pré-História, v. 1, p. 53-89, 1979.

LESSA, A. Conceitos e métodos em curadoria de coleções osteológicas humanas. Arquivos do Museu Nacional, v. 68, n. 1-2, p. 3-16, 2011.

LUND, P. W. Notice sur des ossements humains fossiles trouvés dans une caverne du Brésil. Mémoires de la Societé Royale des Antiquaires du Nord, v. 3, p. 49-77, 1846.

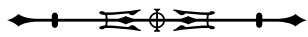


LUND, P. W. Carta do Dr. Lund, escripta da Lagôa Santa (Minas Geraes) a 21 de abril de 1844 - lida na sessão do Instituto de 20 de Junho deste mesmo anno. Revista do Instituto Histórico e Geográfico do Brasil, v. 6, p. 334-342, 1844.

MAHALANOBIS, P. C. On the generalized distance in statistics. Proceedings of the National Institute of Science of India, v. 2, n. 1, 49-55, 1936.

NEVES, W. A. Uma proposta pragmática para cura e recuperação de coleções de esqueletos humanos de origem arqueológica. Boletim do Museu Paraense Emílio Goeldi, Série Antropologia, v. 4, n. 1, p. 3-26, 1988.

NEVES, W. A.; HUBBE, M.; BERNARDO, D.; STRAUSS, A.; ARAUJO, A.; KIPNIS, R. Early human occupation of Lagoa Santa, Eastern Central Brazil: craniometric variation of the initial settlers of South America. In: GRAF, K. E.; KETRON, C. V.; WATERS, M. R. (Eds.). Paleoamerican Odyssey. College Station: Texas A\&M University Press, 2013. p. 397-412.

NEVES, W. A.; ARAUJO, A. G. M.; BERNARDO, D. V.; KIPNIS, R.; FEATHERS, J. K. Rock art at the Pleistocene/Holocene boundary in Eastern South America. PLoS ONE, v. 7, n. 2, p. e32228, 2012 a.

NEVES, W. A.; STRAUSS, A.; BERNARDO, D. V.; ARAUJO, A.; KIPNIS, R. As promessas de Lagoa Santa: Lapa do Santo mostra ocupação humana intensa e o mais antigo grafismo da América. Scientific American Brasil, v. 127, p. 78-81, 2012 b.

NEVES, W. A.; PILÓ, L. B. O povo de Luzia: em busca dos primeiros americanos. Rio de Janeiro: Editora Globo, 2008.

NEVES, W. A.; ARAUJO, A. G. M.; CECCANTINI, G. C. T.; BUENO, L. M. R.; OLIVEIRA, P. E.; KIPNIS, R.; BERNARDO, D. $V$. Origens e microevolução do Homem na América: uma abordagem paleoantropológica III. Relatório científico. São Paulo: Fundação de Amparo à Pesquisa do Estado de São Paulo, 2008. Disponível em: <http://www.bv.fapesp.br/pt/auxilios/1262/ origens-e-microevolucao-do-homem-na-america-uma-abordagempaleoantropologica-iii/>. Acesso em: 1 nov. 2013.

NEVES, W. A.; ARAUjO, A. G. M.; KIPNIS, R.; PILÓ, L. B. O Projeto "Origens e microevolução do Homem na América: uma abordagem paleoantropológica". In: OLIVEIRA, A. P. P. L. (Ed.). Arqueologia e patrimônio de Minas Gerais. Juiz de Fora: Editar, 2007a. p. 73-90.

NEVES, W. A.; HUBBE, M.; PILÓ, L. B. Early Holocene human skeletal remains from Sumidouro Cave, Lagoa Santa, Brazil: history of discoveries, geological and chronological context, and comparative cranial morphology. Journal of Human Evolution, v. 52, n. 1, p. 16-30, 2007b.

NEVES, W. A.; HUBBE, M.; CORREAL, G. Human skeletal remains from Sabana de Bogotá, Colombia: a case of Paleoamerican morphology late survival in South America? American Journal of Physical Anthropology, v. 133, n. 4, p. 1080-1098, 2007c.
NEVES, W. A.; HUBBE, M. Cranial morphology of Early Americans from Lagoa Santa, Brazil: implications for the settlement of the New World. Proceedings of the National Academy of Science of the United States of America, v. 102, n. 51, p. 18309-18314, 2005.

NEVES, W. A.; HUBBE, M.; OKUMURA, M. M. M.; GONZÁLEZJOSÉ, R.; FIGUTI, L.; EGGERS, S.; BLASIS, P. A. D. A new early Holocene human skeleton from Brazil: implications for the settlement of the New World. Journal of Human Evolution, v. 48, n. 4, p. 403-414, 2005.

NEVES, W. A.; KIPNIS, R. Further evidence of a highly cariogenetic diet among Late Paleoindians of Central Brazil. Current Research in the Pleistocene, v. 21, p. 81-83, 2004.

NEVES, W. A.; GONZÁLEZ-JOSÉ, R.; HUBBE, M.; KIPNIS, R.; ARAUJO, A. G. M.; BLASI, O. Early Holocene human skeletal remains from Cerca Grande, Lagoa Santa, Central Brazil, and the origins of the first Americans. World Archaeology, v. 36, n. 4, p. 479-501, 2004.

NEVES, W. A.; HUBBE, M.; ARAUJO, A. G. M. A Late-Paleoindian secondary ritual burial from Lagoa Santa, Minas Gerais, Brazil. Current Research in the Pleistocene, v. 19, p. 83-85, 2002.

NEVES, W. A.; POWELL, J. F.; OZOLINS, E. G. Modern human origins as seen from the peripheries. Journal of Human Evolution, v. 37, n. 1, p. 129-133, 1999.

NEVES, W. A.; CORNERO, S. What did South American Paleoindians eat? Current Research in the Pleistocene, v. 14, p. 93-96, 1997.

NEVES, W. A.; PUCCIARELLI, H. M. Morphological affinities of the first Americans: an exploratory analysis based on early South American human remains. Journal of Human Evolution, v. 21, n. 4, p. 261-273, 1991.

NEVES, W. A.; PUCCIARELLI, H. M. The origin of the first Americans: an analysis based on the cranial morphology of early South American human remains. American Journal of Physical Anthropology, v. 81, n. 2, p. 274, 1990.

NEVES, W. A.; PUCCIARELLI, H. M. Extra-continental biological relationships of early South American human remains: a multivariate analysis. Ciência e Cultura, v. 41, p. 566-575, 1989.

OKUMURA, M. M. M. Diversidade morfológica craniana, microevolução e ocupação pré-histórica da costa brasileira. Pesquisas, Antropologia, São Leopoldo, n. 66, p. 5-66, 2008.

PEREGO, U. A.; ACHILLI, A.; ANGERHOFER, N.; ACCETTURO, M.; PALA, M.; OLIVIERI, A.; KASHANI, B. H.; RITCHIE, K. H.; SCOZZARI, R.; KONG, Q.; MYRES, N. M.; SALAS, A.; SEMINO, O.; BANDELT, H.; WOODWARD, S. R.; TORRONI, A. Distinctive Paleo-Indian migration routes from Beringia marked by two rare mtDNA haplogroups. Current Biology, v. 19, n. 1, p. 1-8, 2009.

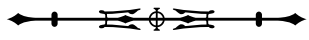


PEREZ, S. I.; BERNAL, V.; GONZALEZ, P. N.; SARDI, M.; POLITIS, G. G. Discrepancy between cranial and DNA data of Early Americans: implications for American peopling. PLoS ONE, v. 4, n. 5, p. e5746, 2009.

PILÓ, L. B. P. W. Lund e a geomorfologia cárstica de Lagoa Santa. O Carste, v. 14, n. 1, p. 12-17, 2002.

PILÓ, L. B.; AULER, A. S.; NEVES, W. A.; WANG, X.; CHENG, H.; EDWARDS, R. L. Geochronology, sediment provenance and fossil emplacement at Sumidouro Cave, a classic late Pleistocene/ early Holocene Paleoanthropological site in Eastern Brazil. Geoarchaeology, v. 20, n. 8, p. 751-764, 2005.

PILÓ, L. B.; AULER, A.; NEVES, W. A.; WANG, X.; CHENG, H.; EDWARDS, R. L. Revisitando a Lapa do Sumidouro: marco paleoantropológico do Quaternário Americano. Revista Brasileira de Paleontologia, v. 7, n. 3, p. 337-348, 2004.

POWELL, J. F. The first Americans: race, evolution and the origin of Native Americans. Cambridge: Cambridge University Press, 2005.

POWELL, J. F.; STEELE, D. G. A multivariate craniometric analysis of North American Paleo-Indian remains. Current Research in the Pleistocene, v. 9, p. 59-62, 1992.

PROUS, A. O povoamento da América visto do Brasil: uma perspectiva crítica. Revista USP, n. 34, p. 8-21, 1997.

PROUS, A. Arqueologia brasileira. Brasília: Editora UnB, 1992.

QUATREFAGES, A. Histoire générale des races humaines: introduction a l'étude des races humaines. Paris: Hennuyer, 1887.

RDEVELOPMENT CORE TEAM. R: a language and environment for statistical computing. Vienna: R Foundation for Statistical Computing, 2010.

REICH, D.; PATTERSON, N.; CAMPBELL, D.; TANDON, A.; MAZIERES, S.; RAY, N.; PARRA, M. V.; ROJAS, W.; DUQUE, C.; MESA, N.; GARCÍA, L. F.; TRIANA, O.; BLAIR, S.; MAESTRE, A.; DIB, J. C.; BRAVI, C. M.; BAILLIET, G.; CORACH, D.; HÜNEMEIER, T.; BORTOLINI, M. C.; SALZANO, F. M.; PETZL-ERLER, M. L.; ACUÑA-ALONZO, V.; AGUILAR-SALINAS, C.; CANIZALESQUINTEROS, S.; TUSIÉ-LUNA, T.; RIBA, L.; RODRÍGUEZCRUZ, M.; LOPEZ-ALARCÓN, M.; CORAL-VAZQUEZ, R.; CANTO-CETINA, T.; SILVA-ZOLEZZI, I.; FERNANDEZ-LOPEZ, J. C.; CONTRERAS, A. V.; JIMENEZ-SANCHEZ, G.; GÓMEZVÁZQUEZ, M. J.; MOLINA, J.; CARRACEDO, Á.; SALAS, A.; GALLO, C.; POLETTI, G.; WITONSKY, D. B.; ALKORTAARANBURU, G.; SUKERNIK, R. I.; OSIPOVA, L.; FEDOROVA, S. A.; VASQUEZ, R.; VILLENA, M.; MOREAU, C.; BARRANTES, R.; PAULS, D.; EXCOFFIER, L.; BEDOYA, G.; ROTHHAMMER, F.; DUGOUJON, J. M.; LARROUY, G.; KLITZ, W.; LABUDA, D.; KIDD, J.; KIDD, K.; DI RIENZO, A.; FREIMER, N. B.; PRICE, A. L.; RUIZ-LINARES, A. Reconstructing Native American population history. Nature, v. 488, n. 7411, p. 370-374, 2012.
RELETHFORD, J. H. Craniometric variation among modern human populations. American Journal of Physical Anthropology, v. 95, n. 1, p. 53-62, 1994.

SADEK-KOOROS, $\mathrm{H}$. Primitive bone fracturing: a method of research. American Antiquity, v. 37, n. 3, p. 369-382, 1972.

STEELE, D. G.; POWELL, J. F. Paleobiology of the first Americans. Evolutionary Anthropology, v. 2, n. 4, p. 138-146, 1993.

STEELE, D. G.; POWELL, J. F. Peopling of the Americas: paleobiological evidence. Human Biology, v. 64, n. 3, p. 303336, 1992.

STRAUSS, A. Possibilidades e limitações interpretativas da Hipótese Saxe/Goldstein. Boletim do Museu Paraense Emílio Goeldi. Ciências Humanas, v. 7, n. 2, p. 525-546, 2012.

STRAUSS, A. As práticas mortuárias dos caçadores-coletores pré-históricos de Lagoa Santa (MG): um estudo de caso do sítio arqueológico "Lapa do Santo". Revista de Arqueologia, v. 24, n. 1, p. 136-139, 2011.

STRAUSS, A. As práticas mortuárias dos caçadores-coletores pré-históricos da região de Lagoa Santa (MG): um estudo de caso do sítio arqueológico "Lapa do Santo". 2010. 723 f. Dissertação (Mestrado em Genética e Biologia Evolutiva) - Universidade de São Paulo, São Paulo, 2010.

STRAUSS, A.; DA-GLORIA, P.; DE OLIVEIRA, R. E.; BERNARDO, D. V.; ARAUJO, A. G. M.; KIPNIS, R.; NEVES, W. A. Lapa do Santo rockshelter: new evidence of perimortem body manipulation in Early Holocene South America. American Journal of Physical Anthropology, v. 144, n. S52, p. 287, 2011.

TAMM, E.; KIVISILD, T.; REIDLA, M.; METSPALU, M.; SMITH, D. G.; MULLIGAN, C. J.; BRAVI, C. M.; RICKARDS, O.; MARTINEZLABARGA, C.; KHUSNUTDINOVA, E. K.; FEDOROVA, S. A.; GOLUBENKO, M. V.; STEPANOV, V. A.; GUBINA, M. A.; ZHADANOV, S. I.; OSSIPOVA, L. P.; DAMBA, L.; VOEVODA, M. I.; DIPIERRI, J. E.; VILLEMS, R.; MALHI, R. S. Beringian standstill and spread of Native American founders. PLoS ONE, v. 9, n. 2, p. e829, 2007.

TEN KATE, H. Sur les crânes de Lagoa-Santa. Bulletins de la Société d'Anthropologie de Paris, v. 8, n. 8, p. 240-244, 1885.

VIRCHOW, R. C. Crania ethnica Americana. Sammlung auserlesener amerikanischer Schädeltypen. Berlin: A. Asher \& Company, 1892.

WAGUESPACK, N. M. Why we're still arguing about the Pleistocene occupation of the Americas. Evolutionary Anthropology, v. 16, n. 2, p. 63-74, 2007.

WALTER, H. V. Arqueologia da região de Lagoa Santa. Rio de Janeiro: Sodegra, 1958.

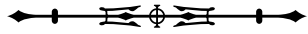


WANG, S.; LEWIS, C. M.; JAKOBSSON, M.; RAMACHANDRAN, S.; RAY, N.; BEDOYA, G.; ROJAS, W.; PARRA, M. V.; MOLINA, J. A.; GALLO, G.; MAZZOTTI, G.; POLETTI, G.; HILL, K.; HURTADO, A. M.; LABUDA, D.; KLITZ, W.; BARRANTES, R.; BORTOLINI, M. C.; SALZANO, F. M.; PETZL-ERLER, M. L.; TSUNETO, L. T.; LLOP, E.; ROTHHAMMER, F.; EXCOFFIER, L.; FELDMAN, M. W.; ROSENBERG, N. A.; RUIZ-LINARES, A. Genetic variation and population structure in Native Americans. Plos Genetics, v. 3, n. 11, p. e185, 2007.
WARD, J. H. Hierarchical grouping to optimize an objective function. Journal of the American Statistical Association, v. 58, n. 301, p. 236-244, 1963.

ZEGURA, S. L.; KARAFET, T. M.; ZHIVOTOVSKY, L. A.; HAMMER, M. F. High-resolution SNPs and microsatellite haplotypes point to a single, recent entry of Native American $Y$ chromosomes into the Americas. Molecular Biology and Evolution, v. 21, n. 1, p. 164-175, 2004. 
Apêndice. Medidas craniométricas (22 medidas tomadas em acordo com o protocolo de Howells, 1973) dos sete espécimes procedentes da Lapa do Santo analisados neste trabalho.

\begin{tabular}{|c|c|c|c|c|c|c|c|}
\hline \multirow{4}{*}{$\begin{array}{l}\text { Variáveis } \\
\text { craniométricas }\end{array}$} & \multicolumn{7}{|c|}{ Identificação } \\
\hline & ST-SEP I & ST-SEP V & ST-SEP XI & ST-SEP XIV & ST-SEP XVII & ST-SEP XXI & ST-SEP XXVI \\
\hline & \multicolumn{7}{|c|}{ Sexo } \\
\hline & $\mathrm{F}$ & $F$ & M & M & $M$ & M & M \\
\hline GOL & 179 & 165 & 189 & 189 & 184 & 187 & 187 \\
\hline $\mathrm{NOL}$ & 175 & 163 & 188 & 186 & 181 & 183 & 185 \\
\hline $\mathrm{XCB}$ & 135 & 120 & 134 & 139 & 124 & 127 & 130 \\
\hline XFB & 122 & 105 & 117 & 120 & 105 & 113 & 112 \\
\hline $\mathrm{NPH}$ & 61 & - & 69 & - & 74 & 64 & 65 \\
\hline $\mathrm{NLH}$ & 44 & - & 50 & - & 56 & 46 & 49 \\
\hline $\mathrm{OBH}$ & 33 & - & 34 & - & 38 & 32 & 34 \\
\hline OBB & 40 & 38 & 40 & - & 42 & 43 & 41 \\
\hline $\mathrm{MDH}$ & 27 & 16 & 20 & - & 14 & 21 & 25 \\
\hline MDB & 9 & 8 & 16 & 14 & 15 & 14 & 15 \\
\hline FMB & 98 & 96 & 94 & 109 & 100 & 100 & 100 \\
\hline NAS & 19 & 19 & 17 & 17 & 16 & 15 & 16 \\
\hline DKB & 23 & 23 & 27 & 28 & 22 & 25 & 22 \\
\hline WMH & 19 & - & 26 & - & 25 & 25 & 23 \\
\hline sOS & 9 & 7 & 7 & 8 & 6 & 10 & 8 \\
\hline GLS & 4 & 2 & 3 & 5 & 4 & 4 & 4 \\
\hline FRC & - & 105 & 120 & 116 & 109 & 107 & 125 \\
\hline FRS & - & 24 & 29 & 27 & 23 & 24 & 24 \\
\hline FRF & - & 50 & 51 & 47 & 56 & 47 & 47 \\
\hline PAC & - & 111 & 120 & 120 & 102 & 127 & 111 \\
\hline PAS & - & 27 & 22 & 26 & 22 & 26 & 21 \\
\hline PAF & - & 53 & 50 & 59 & 40 & 46 & 52 \\
\hline
\end{tabular}

